\title{
VALIDAÇÃO DA METODOLOGIA DE CITOMETRIA DE FLUXO PARA AVALIAÇÃO DA CONTAGEM BACTERIANA DO LEITE CRÚ
}

\author{
LAERTE DAGHER CASSOLI
}

Dissertação apresentada à Escola Superior de Agricultura

“Luiz de Queiroz”, Universidade de São Paulo, para obtenção do título de Mestre em Agronomia, Área de Concentração: Ciência Animal e Pastagens.

P I R A C I C A B A

Estado de São Paulo - Brasil

Junho - 2005 


\title{
VALIDAÇÃO DA METODOLOGIA DE CITOMETRIA DE FLUXO PARA AVALIAÇÃO DA CONTAGEM BACTERIANA DO LEITE CRÚ
}

\section{LAERTE DAGHER CASSOLI}

Engenheiro Agrônomo

Orientador: Prof. Dr. PAULO FERNANDO MACHADO

\begin{abstract}
Dissertação apresentada à Escola Superior de Agricultura “Luiz de Queiroz”, Universidade de São Paulo, para obtenção do título de Mestre em Agronomia, Área de Concentração: Ciência Animal e Pastagens.
\end{abstract}

P I R A C I C A B A

Estado de São Paulo - Brasil

Junho - 2005 
Dados Internacionais de Catalogação na Publicação (CIP) DIVISÃO DE BIBLIOTECA E DOCUMENTAÇÃO - ESALQ/USP

\section{Cassoli, Laerte Dagher}

Validação da metodologia de citometria de fluxo para avaliação da contagem bacteriana do leite cru / Laerte Dagher Cassoli. - - Piracicaba, 2005.

46 p. : il.

Dissertação (mestrado) - - Escola Superior de Agricultura Luiz de Queiroz, 2005.

Bibliografia.

1. Bacteriologia 2. Citometria de fluxo 3. Leite 4. Microbiologia de alimento I. Título

CDD 637.1277

"Permitida a cópia total ou parcial deste documento, desde que citada a fonte - $\mathrm{O}$ autor" 
"Somos o que repetidamente fazemos.

A excelência, portanto, não é um feito, mas um hábito"

Aristóteles 


\section{AGRADECIMENTOS}

Ao Prof. Dr. Paulo Fernando Machado pela orientação e suporte. Sem os conhecimentos gerenciais e de administração do tempo que me foram passados, certamente não seria possível concluir tal projeto.

A toda a equipe da Clínica do Leite que desempenha o seu trabalho com excelência e sem o qual não seria possível a realização de mais este projeto. Parabéns a todos vocês.

Ao amigo e estatístico Arlei pelo suporte na análise estatística e revisão dos trabalhos.

Aos colegas Ana Carolina e Luiz Carlos, pelo auxílio na tradução, formatação e revisão dos trabalhos.

Aos meus amigos, Carlão, Karyne, Daine, Rafael, Mac, Fiat e Jony pelo apoio, conselhos e momentos de distração.

A Bentley Instruments (Darci, Tod e Pierre) pelo apoio técnico e financeiro necessários para a execução do projeto.

Aos meus pais pelo apoio e suporte durante toda a minha vida, além de serem um dos maiores incentivadores de meu trabalho.

E a minha esposa Clarissa pelo apoio constante, dedicação, e por ser meu porto seguro nas horas difíceis. Muito obrigado e considere-se parte importante para o sucesso do meu trabalho. 


\section{SUMÁRIO}

Página

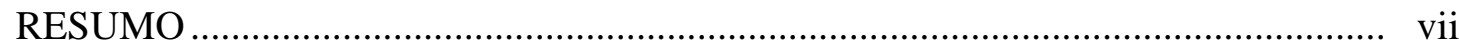

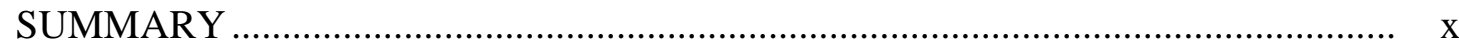

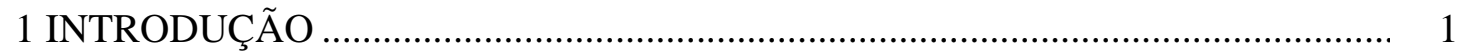

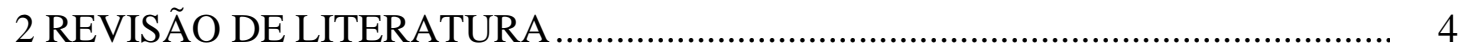

2.1 Avaliação da qualidade do leite ........................................................................ 4

2.2 Qualidade microbiológica do leite ................................................................... 5

2.3 Método de referência na determinação da contagem bacteriana do leite................. 7

2.4 Método de citometria de fluxo na determinação da contagem bacteriana do leite.. 8

2.5 Limites legais de contagem bacteriana total no leite .......................................... 10

2.6 Correlação entre os métodos de referência e de citometria de fluxo na determinação da contagem bacteriana do leite............................................................. 11

2.7 Conservação de amostras para determinação da contagem bacteriana através da metodologia de citometria de fluxo ...................................................................... 12

3 CONSERVAÇÃO DE AMOSTRAS DE LEITE PARA DETERMINAÇÃO DA CONTAGEM BACTERIANA TOTAL PELO MÉTODO DE CITOMETRIA DE

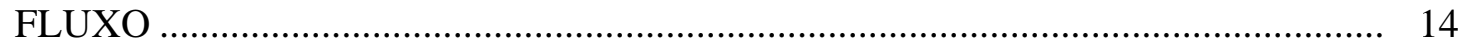

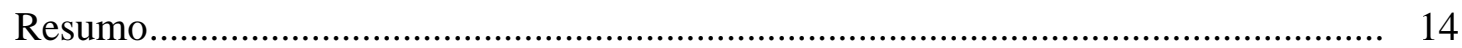

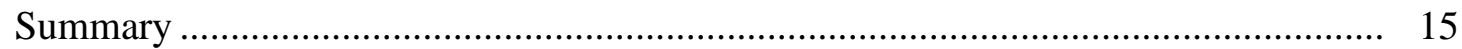

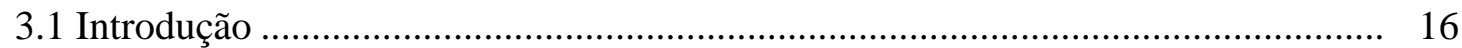

3.2 Material e Métodos ................................................................................... 18

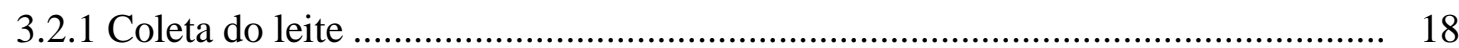




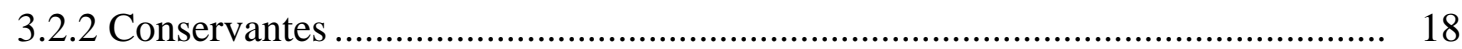

3.2.3 Temperatura de armazenamento .............................................................. 19

3.2.4 Tempo entre a coleta e a análise ................................................................. 19

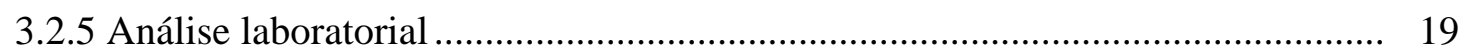

3.2.6 Análise estatística....................................................................................... 19

3.3 Resultados e Discussão ............................................................................... 20

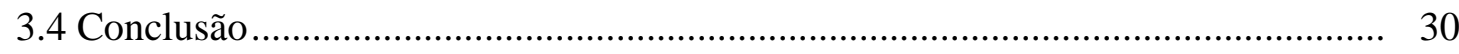

4 CORRELAÇÃO ENTRE OS MÉTODOS DE REFERÊNCIA E DE CITOMETRIA DE FLUXO PARA DETERMINAÇÃO DA CONTAGEM BACTERIANA TOTAL NO LEITE CRU .............................................................. 31

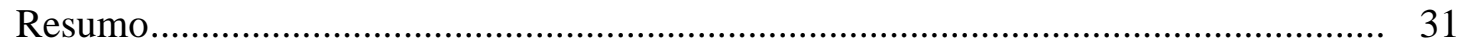

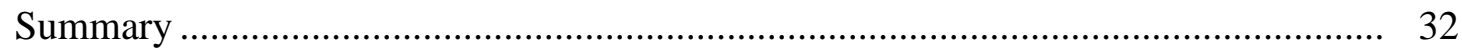

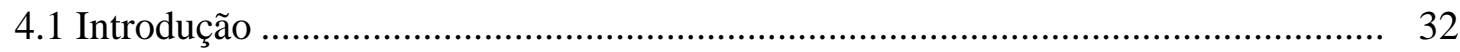

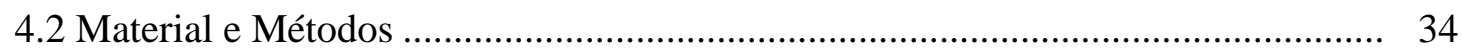

4.2.1 Coleta e conservação das amostras de leite........................................................... 34

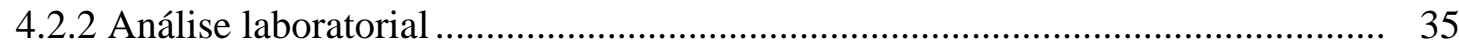

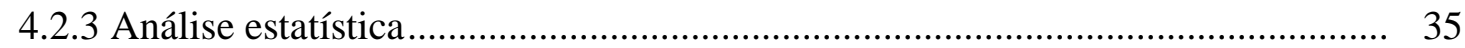

4.3 Resultados e Discussão ..................................................................................... 36

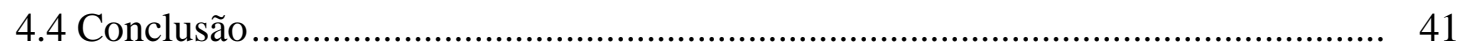

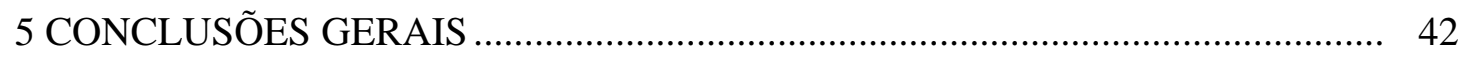

REFERÊNCIAS BIBLIOGRÁFICAS ............................................................ 43 


\title{
VALIDAÇÃO DA METODOLOGIA DE CITOMETRIA DE FLUXO PARA AVALIAÇÃO DA CONTAGEM BACTERIANA DO LEITE CRÚ
}

\author{
Autor: LAERTE DAGHER CASSOLI
}

Orientador: Prof. Dr. PAULO FERNANDO MACHADO

\section{RESUMO}

O objetivo do trabalho foi avaliar a utilização da metodologia de citometria de fluxo na determinação da contagem bacteriana total (CBT) do leite cru. No primeiro estudo foi avaliado o efeito da temperatura de armazenamento, da idade da amostra e do tipo conservante sobre a CBT. Também foi estudada a possibilidade de se utilizar uma única amostra de leite para a realização das análises previstas na Instrução Normativa 51 (IN-51). Foram testadas, três temperaturas de armazenamento $\left(0^{\circ} \mathrm{C}-\right.$ congelado, $7^{\circ} \mathrm{C}-$ resfriamento e $24{ }^{\circ} \mathrm{C}$ - ambiente), três conservantes (bronopol, azidiol e sem conservante) e quatro tempos entre a coleta e a análise (idade da amostra) (um (D1), três (D3), cinco (D5) e sete (D7) dias). Foi considerado tratamento controle para análise de CBT, amostras refrigeradas, com azidiol e com um dia de idade. Para as análises de composição e CCS, o tratamento controle foram amostras refrigeradas, com bronopol e com um dia de idade. Os resultados indicaram que será necessária a coleta de duas amostras, uma destinada à determinação de CCS e composição, contendo bronopol e, outra, para CBT, contendo azidiol. A amostra para CBT poderá ser analisada em até sete dias após a coleta, desde que mantida sob refrigeração à $7^{\circ} \mathrm{C}$. Deve-se evitar o aquecimento ou o congelamento da amostra para CBT, bem como garantir a adição do azidiol. O segundo estudo teve como objetivo estabelecer a correlação entre os métodos 
de referência e de citometria de fluxo na determinação da CBT. Amostras coletadas nos meses de junho à setembro $(n=155)$ foram agrupadas considerando-se estação da seca e as coletadas nos meses de novembro e dezembro $(n=68)$, estação das águas. Foram realizadas análises simultâneas pelos métodos de referência (contagem padrão em placas) e de citometria de fluxo (equipamento Bactocount), sendo os resultados expressos em unidades formadoras de colônia (UFC) e contagem individual de bactérias (CIB), respectivamente. As equações lineares de correlação entre a CIB e UFC foram semelhantes nas estações, indicando que uma única equação pode ser utilizada ao longo do ano para transformar os resultados de CIB para UFC. A equação linear obtida foi: $\log (\mathrm{UFC})=\log (\mathrm{CIB}) \times 0,7224+1,4617$ com coeficiente de correlação de 0,8125. A acurácia do equipamento Bactocount na estimativa do valor de referência, expressa pelo erro padrão $(\mathrm{s}(\mathrm{y}, \mathrm{x}))$, foi de $0,309 \log \mathrm{UFC} / \mathrm{mL}$. Os resultados mostraram que o equipamento Bactocount pode ser calibrado para expressar os resultados em UFC e com isso ser utilizado no monitoramento da qualidade do leite. 


\title{
EVALUATION OF FLOW CYTOMETRY AS A METHOD FOR TOTAL BACTERIAL COUNT OF RAW MILK
}

\author{
Author: LAERTE DAGHER CASSOLI \\ Adviser: Prof. Dr. PAULO FERNANDO MACHADO
}

\section{SUMMARY}

The objective of this study was to evaluate the utilization of electronic flow cytometry to determine total bacterial count (TBC) of raw milk. In the first experiment, the effect of storage temperature, sample age and milk preservative type on TBC were evaluated. Additionally, the use of a single milk sample to performance regulatory milk analysis under the Normative Instruction 51 (NI-51) was tested. Effects were standardized as: three storage temperatures $\left(0^{\circ} \mathrm{C}-\right.$ freezer, $7^{\circ} \mathrm{C}-$ refrigerator and $24^{\circ} \mathrm{C}-$ room temperature), four sample ages (1 (D1), 3 (D3), 5 (D5) and 7 (D7) days) and three milk preservatives (bronopol, azidiol and no preservative). Control treatment for TBC analysis was defined as refrigerated milk samples containing azidiol with 1 day of storage. For determination of milk components and somatic cell count (SCC), control treatment was defined as refrigerated milk samples containing bronopol with 1 day of storage. Results of the first experiment showed that two milk samples are necessary to performance regulatory milk analysis under the NI-51; one containing bronopol should be used for determination of milk components and SCC, and other containing azidiol for TBC. Milk samples used for TBC can be tested until 7 days after sampling when they are kept at $7^{\circ} \mathrm{C}$. Freezing or heating milk samples for TBC analysis should be avoided and addition of azidiol is always necessary. The second experiment was designed to determine a correlation between two methods of TBC, electronic flow cytometry and standard plate count. Milk samples collected from June to September $(\mathrm{n}=155)$ were named as dry season samples and milk samples collected in November and December (n $=68$ ) were named as rainy season samples. Each milk sample was used to run both methods of TBC. Results were expressed as individual bacterial count (IBC) and colony 
forming unit (CFU) for electronic flow cytometry (Bactocount) and standard plate count, respectively. The linear equations of correlation between IBC and CFU had similar patterns in both seasons, dry and rainy, indicating that a single equation can be used to transform IBC results in CFU along the year. The linear equation was defined as $\log (\mathrm{CFU})=0.7224 \times \log (\mathrm{IBC})+1.4617$ with coefficient of correlation of 0.8125 . The accuracy of Bactocount in estimating reference values, denoted by the standard error $(\mathrm{s}(\mathrm{y}, \mathrm{x})$ ), was $0.309 \log \mathrm{CFU} / \mathrm{mL}$. The results showed that Bactocount can be calibrated to express TBC readings in CFU and, consequently, be used to monitor milk quality. 


\section{INTRODUÇÃO}

Um dos fatos mais importantes para o setor leiteiro nos últimos anos foi a aprovação da Instrução Normativa 51 (IN-51), do Ministério da Agricultura Pecuária e Abastecimento (MAPA), que determina novas variáveis de avaliação da qualidade do leite cru. De acordo com a IN-51, análises de contagem bacteriana total (CBT), contagem de células somáticas (CCS) e composição, de todo leite cru produzido no país e processado em estabelecimentos sob fiscalização federal, deverão ser realizadas mensalmente em um dos laboratórios credenciados pelo MAPA (BRASIL, 2002).

Para atender a demanda por estas análises, o MAPA criou a Rede Brasileira de Laboratórios de Análise da Qualidade do Leite (RBQL), composta atualmente por sete laboratórios centralizados que possuem equipamentos automatizados de última geração e de alto rendimento analítico.

A determinação da CBT poderá ser efetuada por meio do equipamento Bactocount (Bentley Instruments), o qual emprega a técnica de citometria de fluxo. Esta técnica consiste na adição de brometo de etídio (corante específico de DNA e RNA) ao leite, para que o DNA e RNA das bactérias sejam corados. O leite com o corante é injetado num capilar acoplado a um sistema óptico, que recebe, constantemente, um feixe de laser. Ao passar por este feixe, cada bactéria emite fluorescência, a qual é captada pelo sistema óptico (Barrientos et al., 2000; Broutin, 2004; Gunasekera et al., 2000; Suhren et al., 1999), e com isso o número de bactérias é determinado, sendo expresso em contagem individual de bactérias (CIB).

Esta metodologia analítica possibilita a utilização de conservantes bacteriostáticos que reduzem a atividade metabólica das bactérias, prolongando a vida útil da amostra destinada para tal análise. O conservante mais recomendado, atualmente, 
é o azidiol. Há citações na literatura de que amostras conservadas com azidiol podem ser analisadas em até quatro dias após a coleta, se mantidas sob refrigeração à $4{ }^{\circ} \mathrm{C}$ (Barcina et al., 1987; Gonzalo et al., 2003; Ninane et al., 2000). Em alguns países não se utiliza conservante, mas unicamente a refrigeração como mecanismo de preservação da amostra (Estados Unidos, 2001). Nestes casos, a distância entre as fazendas e os laboratórios são curtas, o que possibilita a análise em no máximo 48 horas após a coleta, como recomendado pela International Dairy Federation (International Dairy Federation, 1995).

No método de referência para CBT, uma alíquota de leite é distribuída em placa com meio de cultura e incubada a $30{ }^{\circ} \mathrm{C}$ por 72 horas (International Dairy Federation, 1991). Bactérias viáveis e que se multiplicam nestas condições, desenvolvem colônias que são enumeradas, sendo o resultado expresso em unidades formadoras de colônia (UFC). Um aspecto negativo do método de referência é o de subestimar a quantidade total de bactérias no leite, uma vez que nem sempre uma colônia é originada de apenas uma única bactéria. Este é dos motivos porque a CIB pode ser duas ou três vezes superior ao número de UFC (Gunasekera et al., 2003; Broutin, 2004).

O limite legal para a CBT previsto na IN-51, foi estabelecido em UFC. Isto implica na necessidade de se desenvolver uma equação de correlação entre os métodos de referência e de citometria, para que os resultados expressos em CIB sejam transformados em UFC.

Países da Europa vêm adotando diferentes estratégias para adequação desta nova metodologia. Na Alemanha, por exemplo, foi elaborada uma única equação de calibração para todos os laboratórios. Na França, Holanda e Bélgica, no entanto, cada laboratório desenvolveu a equação para seus equipamentos (Broutin, 2004).

Vários trabalhos mostram uma boa correlação entre os métodos automatizado e o de contagem em placas, porém, neles, ressalta-se a importância de se utilizar um grande número de amostras de leite da região que será monitorada, uma vez que existem vários fatores que podem interferir nesta correlação (Broutin, 2004; Ninane et al., 2000; Gunasekera et al., 2000; Suhren et al., 1999). Os principais fatores citados são a microbiota predominante no leite (Gram positiva ou negativa), tamanho e formato da 
célula bacteriana, assim como características de agregação destas células (Suhren \& Reichmuth, 2000).

Em função do exposto, o presente trabalho teve como objetivo verificar a possibilidade de utilizar uma única amostra conservada com azidiol para determinação das análises previstas na IN-51, o que reduziria custos com material de coleta e transporte. Além disso, verificar os efeitos da temperatura de armazenamento e a idade da amostra sobre a CBT. Outro objetivo do trabalho seria determinar a equação de correlação entre o método referência (UFC) e o método de citometria de fluxo (CIB). Com esta equação, os resultados de CIB podem ser transformados em UFC e utilizados no monitoramento da qualidade do leite proposto pela IN-51. 


\section{REVISÃO DE LITERATURA}

\subsection{Avaliação da qualidade do leite}

O Ministério da Agricultura Pecuária e Abastecimento (MAPA), através da aprovação da Instrução Normativa 51(IN-51), definiu novos parâmetros de qualidade para o leite cru resfriado, bem como novas variáveis de avaliação da sua qualidade. A partir de julho de 2005, será obrigatória a análise de amostra de leite de cada produtor que destina seu produto para estabelecimento sob fiscalização federal, em laboratório oficial, para determinação da composição do leite (teores de gordura, proteína, e sólidos totais), contagem de células somáticas (CCS) e contagem bacteriana total (CBT).

A análise de CBT no leite cru, já é exigida para a produção de leite tipo “A” e “B”, sendo o limite de 10 mil e $500 \mathrm{mil} \mathrm{UFC/mL}$, respectivamente. Para o leite tipo "C", não existe limite para tal variável até o momento. Com a aprovação da IN-51, foi estabelecido um limite máximo de CBT de $1.000 \mathrm{mil} \mathrm{UFC/mL} \mathrm{para} \mathrm{o} \mathrm{leite} \mathrm{cru}$ refrigerado (leite tipo “C”). Para CCS, será adotado um limite máximo de 1.000 mil células/mL (BRASIL, 2002). Apesar do limite proposto para CBT ser muito superior ao limite internacional, que é de $100 \mathrm{mil}$ UFC/mL, a obrigatoriedade desta análise já é um grande avanço para o setor, e irá proporcionar o conhecimento da qualidade microbiológica do leite brasileiro.

Estas variáveis de avaliação da qualidade do leite são amplamente utilizadas em outros países. Por exemplo, nos EUA, a determinação da CCS começou a ser realizada em 1967 e, o primeiro limite legal foi definido em 1986.

Para implantação da IN-51, o MAPA criou a Rede Brasileira de Laboratórios de Análise da Qualidade do Leite (RBQL). A RBQL será responsável pela análise de todo o 
leite cru produzido no país, sendo composta atualmente por sete laboratórios centralizados. Estes laboratórios possuem equipamentos automatizados de última geração e de alto rendimento analítico.

Paralelamente a iniciativa do MAPA, indústrias processadoras vêm desenvolvendo programas de pagamento por qualidade com o objetivo de incentivar a melhoria da qualidade do leite de seus fornecedores (Dairy Partners of America, 2004). Estes programas definem classes de qualidade para cada variável, com remuneração diferenciada para cada classe. Por exemplo, o programa proposto por uma indústria prevê que o leite com CBT inferior a $100 \mathrm{mil} \mathrm{UFC/mL} \mathrm{será} \mathrm{remunerado} \mathrm{acima} \mathrm{de} \mathrm{certo}$ valor base, enquanto que o leite com contagem superior a $400 \mathrm{mil}$ UFC/mL será penalizado, sendo remunerado abaixo do valor base. Este conceito também foi aplicado às outras variáveis como teor de gordura, proteína e CCS.

A iniciativa do MAPA e das indústrias, certamente, irá promover a melhoria da qualidade do leite do país, possibilitando, inclusive, a inserção do país no comércio internacional.

\subsection{Qualidade microbiológica do leite}

Em condições normais, o leite é estéril ao ser secretado nos alvéolos do úbere (Internacional Dairy Federation, 1980). Contudo, ao ser ordenhado, o leite pode se contaminar por um pequeno e bem definido número de microrganismos, provenientes dos canais lactíferos, da cisterna da glândula e canal do teto (Brito, 1999; Fonseca \& Santos, 2000). Quando o animal está sadio, esta contaminação varia de 5 a 20 UFC/mL sendo, portanto, de pouca importância no aspecto quantitativo (Prata, 2001). Entretanto, em condições inadequadas da saúde da glândula mamária, sistema de manejo e condições de higiene adotadas na fazenda, este número pode se elevar até vários milhares (Slaghuis, 1996; Fonseca \& Santos, 2000; Murphy \& Boor, 2000; Edmonson, 2002).

Ressalta-se também, que o leite é um meio de cultura ideal para o crescimento de bactérias e outros microrganismos (Hilerton, 2000). Por exemplo, a população de 
coliformes dobra a cada 20 minutos no leite em uma temperatura média de $30{ }^{\circ} \mathrm{C}$ (Brito, 1999). Em função do número e do tipo de microrganismos, alterações indesejáveis são produzidas na aparência, sabor ou odor do leite ou de seus derivados. Além disso, alguns microrganismos podem representar risco à saúde do consumidor (Fonseca \& Santos, 2000).

Assim sendo, a qualidade microbiológica do leite pode ser enfocada sob dois diferentes prismas: a qualidade industrial e o risco à saúde pública (Fonseca \& Santos, 2000). No que se refere à indústria, vários pesquisadores têm enumerado os principais prejuízos devidos à alta carga microbiana, destacando-se os problemas com acidificação e coagulação, produção de gás, geleificação, sabor amargo, coagulação sem acidificação, aumento da viscosidade, alteração de cor, produção de sabores e odores variados, entre outros. Estas alterações causam diminuição da vida de prateleira e diminuem o rendimento industrial (Prata, 2001; Gigante, 2004).

Esperava-se que, com o processo de coleta a granel do leite e conseqüente melhoria nas condições de transporte e de refrigeração, os problemas em decorrência da carga microbiana do leite fossem amenizados, porém isto não ocorreu. Apesar da adoção do armazenamento e coleta a granel diminuir a proliferação de bactérias mesofílicas (aquelas que possuem crescimento ótimo em temperatura média de $35^{\circ} \mathrm{C}$ ), este processo promove a seleção de bactérias psicrotróficas (aquelas que possuem crescimento ótimo em temperatura média de $7^{\circ} \mathrm{C}$ ). Esses microrganismos possuem alta capacidade de produção de enzimas que diminuem o valor nutritivo e o rendimento industrial do leite e de seus derivados (Collins et al., 1993; Celestino et al., 1997; Fonseca \& Santos, 2000; Prata, 2001).

Além dos problemas de qualidade nas indústrias, as condições inadequadas de manejo na ordenha, no armazenamento e no transporte do leite podem acarretar risco à saúde pública, devido à ação de bactérias patogênicas, especialmente quando o leite é consumido cru. Entre as principais bactérias que podem ser encontradas no leite destacam-se: Listeria, Salmonella, Staplylococcus aureus, Brucella, Mycobaterium, entre outras (Brito, 1999). 
Neste contexto, o conhecimento da carga microbiana do leite constitui em uma importante ferramenta para avaliar a qualidade do leite produzido.

\subsection{Método de referência na determinação da contagem bacteriana do leite}

Os métodos utilizados para a determinação da qualidade microbiológica podem ser divididos em dois grupos, os qualitativos e os quantitativos.

Entre os testes qualitativos, destacam-se: o teste da redutase, teste da fermentação e o teste da acidez. Apesar da praticidade de realização, estes testes são subjetivos e indiretos, sendo utilizados apenas para um diagnóstico geral da qualidade do leite (Fonseca \& Santos, 2000).

Dentre os testes quantitativos, destaca-se a contagem bacteriana total (CBT), em que são estimados o número de unidades formadoras de bactérias por mililitros de leite (UFC/mL) (BRASIL, 1999). Para esta determinação, existem vários métodos disponíveis, dentre eles, a contagem bacteriana em placa (CBP) é considerado o método referência. A CBP determina o conteúdo de bactérias aeróbias no leite. Amostras de leite, geralmente em várias diluições, são semeadas em um meio de cultura, incubadas por $48 \mathrm{~h}$ a $32{ }^{\circ} \mathrm{C}$. Após a incubação, o número de colônias bacterianas é contado (Brito, 1999; Hilerton, 2000). Este procedimento pode subestimar a quantidade de bactérias presentes no leite, pois apenas bactérias viáveis e que se multiplicam nas condições de cultivo, formam colônias. Também, a característica de agregação pode subestimar a contagem, sendo que uma colônia pode ter sido originada de várias bactérias (Hilerton, 2000). Destaca-se que, devido à utilização de um meio de cultura simples, ocorre competição entre as espécies presentes, sobressaindo-se bactérias que encontram condições mais favoráveis (Prata, 2001). Autores citam outras desvantagens do método de referência, como o baixo rendimento analítico e a grande demanda por mão-de-obra (Broutin, 2004).

A partir da década de 70, métodos rápidos começaram a surgir, utilizando-se do mesmo princípio da CBP. Entre estes, destacam-se o Petrifilm ${ }^{\circledR}$ e SimPlate ${ }^{\circledR}$, que apresentam como vantagens, a praticidade de realização e menor tempo para leitura 
(24h). No entanto, o meio de cultura empregado nestes testes limita o desenvolvimento de alguns grupos de bactérias, subestimando a real carga microbiana do leite.

Por estas limitações, Suhren et al. (2000) citam que a CBP não expressa a real qualidade bacteriológica do leite, apesar de ser utilizado internacionalmente como método de referência.

\subsection{Método de citometria de fluxo na determinação da contagem bacteriana do leite}

Novas metodologias para análise do leite vêm sendo desenvolvidas nos últimos anos com o objetivo de aumentar a capacidade analítica e obter resultados confiáveis num menor espaço de tempo. A citometria de fluxo é um exemplo disto, uma vez que já vinha sendo aplicada em análises humanas e, mais recentemente, foi adaptada e empregada em análises na área animal.

Os primeiros equipamentos surgiram durante a Segunda Guerra Mundial e tinham como objetivo, identificar a presença de bactérias e esporos no ar (armas biológicas). Ao longo dos anos, novos equipamentos foram desenvolvidos para identificação de microrganismos em meio fluido e, mais recentemente, no leite (Mackenzie et al., 1987; Suhren et al., 1998; Guansakera et al., 2000).

A citometria de fluxo consiste na medição de características celulares, quando estas se encontram suspensas em meio fluido (Barrientos et al., 2000). O leite e as células bacterianas em suspensão são injetados em um capilar acoplado a um sistema óptico. O capilar recebe continuamente um feixe de laser (Figura 1), que atinge cada bactéria que passa pelo capilar de fluxo. 


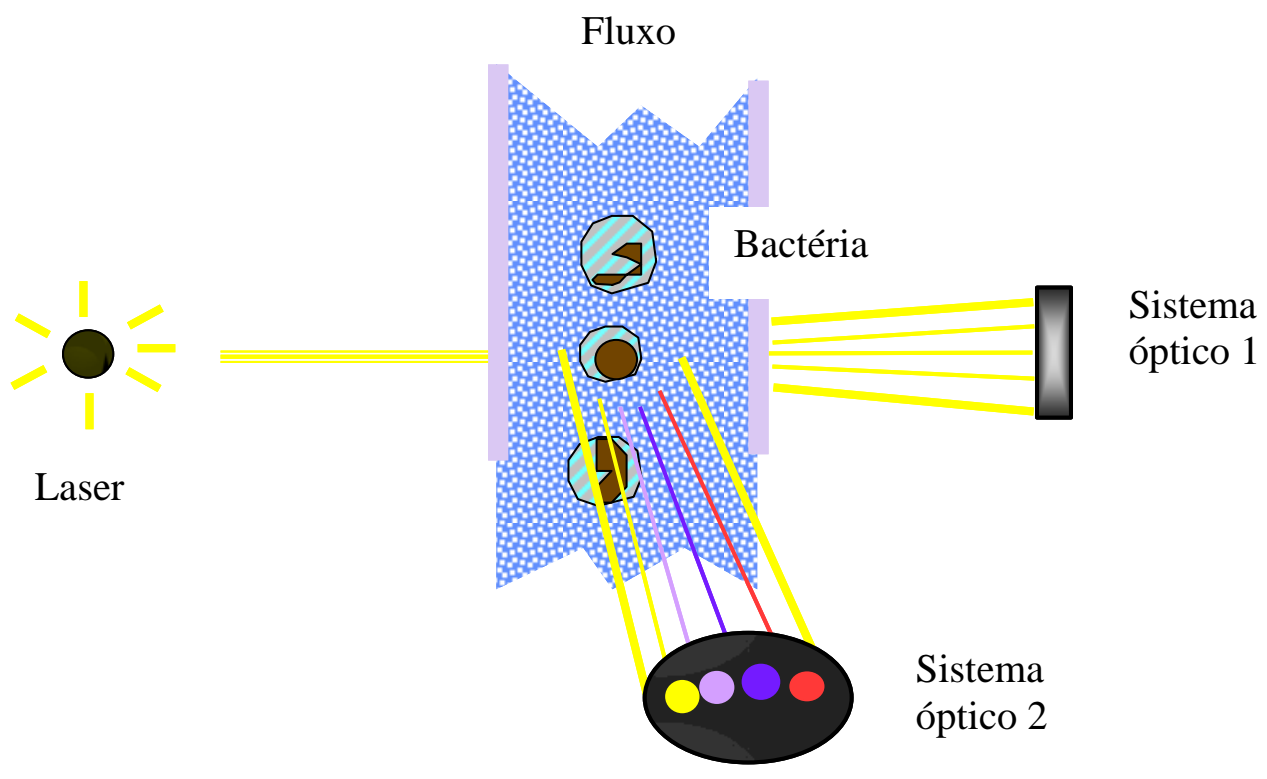

Figura 1- Partes integrantes do equipamento de citometria de fluxo (capilar de fluxo, laser e sistema óptico)

O sistema óptico 1, que se localiza na mesma direção do laser, coleta informações referentes ao tamanho e o número de células. Já o sistema óptico 2, que se localiza a $90^{\circ}$ do feixe de luz, coleta informações referentes à complexidade da célula, como características da parede celular e número de organelas presentes.

Nesta técnica são utilizados corantes fluorescentes específicos, como é o caso do brometo de etídio. O corante penetra nas células bacterianas e se liga ao RNA e DNA. Quando excitadas pelo laser, as células passam a emitir radiação em comprimento de onda de $620 \mathrm{~nm}$ que é coletada pelo sistema óptico (Barrientos et al., 2000). Para que ocorra a penetração do corante nas células, é necessário realizar tratamento do leite com enzimas proteolíticas para eliminação das proteínas e com detergentes, para eliminação da gordura do leite. As enzimas também atuam na degradação das células somáticas, que são totalmente destruídas durante o processo de sonificação (Dansen et al., 1991; 
Barrientos et al., 2000; Ninane et al., 2000). A radiação emitida pelas células bacterianas é coletada pelo sistema óptico, transferida para o sistema de filtros, e, posteriormente, transformada em impulso elétrico pelo sistema eletrônico. Os impulsos por sua vez, são transformados em número de bactérias e este, relacionado ao volume de leite analisado. Os resultados emitidos por estes equipamentos são expressos em número de bactérias por $\mathrm{mL}$ de leite e representam a contagem individual de bactérias (CIB).

A grande vantagem destes equipamentos é o baixo custo da análise e o elevado rendimento analítico, sendo possível obter a CBT em cerca de 12 minutos e analisar 150 amostras por hora (Bentley Instruments, 2004). Em vários países da Europa e também nos EUA, estes equipamentos vêm sendo utilizados em grande escala, uma vez que, nestes países se realiza o monitoramento da qualidade de todo o leite cru produzido, o que representa um grande número de amostras.

Alguns autores citam como desvantagem da metodologia de citometria de fluxo, o fato dos resultados serem expressos em CIB, enquanto que os padrões internacionais de qualidade microbiológica são definidos geralmente em unidades formadoras de colônia (Suhren et al., 2000; Broutin, 2004).

\subsection{Limites legais de contagem bacteriana total no leite}

A contagem padrão em placas foi a principal metodologia estudada e utilizada nas últimas décadas para se determinar a contagem de bactérias presentes no leite, sendo considerada a metodologia de referência para este tipo de análise. Por este motivo, o limite legal de CBT em vários países, foi definido em unidades formadoras de colônia (UFC/mL) (Broutin, 2004). No Brasil, o MAPA, através da IN-51, também definiu o limite legal para CBT em UFC.

Com a crescente utilização da metodologia de citometria de fluxo, cujo resultado é fornecido em CIB, as legislações estão sendo adaptadas, uma vez que a CIB pode ser de duas a três vezes superior ao número de UFC (Guansakera et al., 2000). 
No Canadá, o limite estabelecido de CBT é de $50 \mathrm{mil} \mathrm{UFC} / \mathrm{mL}$. Ao adotar a citometria de fluxo, um novo limite em CIB, de 100 mil bactérias/mL (Leslie, 2001), foi criado.

Países como o Reino Unido e Noruega adotaram um único limite em CIB e não mais em UFC (Broutin, 2004). Por outro lado, alguns países desenvolveram equações de correlação entre os métodos, com o objetivo de transformar os resultados de CIB em UFC, sem alterar os limites legais, como é o caso da Alemanha, França, Holanda e Bélgica (Broutin, 2004).

No Brasil, a proposta inicial é desenvolver uma equação de correlação entre os métodos para que os resultados obtidos pelo equipamento em CIB possam ser transformados em UFC.

\subsection{Correlação entre os métodos de referência e de citometria de fluxo na determinação da contagem bacteriana do leite}

Alguns trabalhos demonstram forte correlação entre o método de citometria de fluxo e o método referência (Ninane et al., 2000; Gunasekera et al., 2003; Broutin, 2004).

A acurácia dos equipamentos disponíveis em estimar o valor de referência, expressa pelo erro padrão $(\mathrm{s}(\mathrm{y}, \mathrm{x}))$, variou de 0,167 a $0,30 \log \mathrm{UFC} / \mathrm{mL}$ em trabalhos realizados na Europa (Niname et al., 2000; Suhren et al., 2000; Trossat et al. 2002). O fabricante de um dos equipamentos sugere um erro padrão máximo de 0,25 log UFC/mL (Broutin, 2004).

Suhren et al. (2000) ressaltam a importância de se utilizar um grande número de amostras em estudos de correlação entre os métodos, pois vários fatores podem interferir na correlação, como é o caso do nível de contaminação bacteriana. Em amostras de leite onde a contagem bacteriana é reduzida, há uma predominância de bactérias Grampositivas, enquanto que em amostras de alta contagem, predominam bactérias Gramnegativas. Segundo os autores, os equipamentos automatizados subestimam a contagem de bactérias Gram-negativas e superestima as Gram-positivas, quando comparado ao 
método de referência. No trabalho realizado por Trossat et al. (2002), em que a acurácia do equipamento em estimar o valor de referência foi de $0,16 \log \mathrm{UFC} / \mathrm{mL}, 78 \%$ das amostras possuíam contagem bacteriana abaixo de $50 \mathrm{mil} \mathrm{UFC} / \mathrm{mL}$ e apenas $3 \%$ das amostras apresentavam contagem superior a $300 \mathrm{mil} \mathrm{UFC} / \mathrm{mL}$. Esta variação de contaminação bacteriana é, provavelmente, bem menor do que a observada no leite produzido no Brasil.

Outros fatores, como atividade metabólica das células bacterianas, características de agregação e microbiota predominante, também podem afetar a correlação (Suhren et al., 2000). Isto mostra que devem ser utilizadas no estudo de correlação amostras representativas da região que será monitorada

Suhren et al. (2000) sugerem que seja realizado monitoramento permanente da correlação entre os métodos, efetuando ajuste na equação de correlação, quando necessário. Segundo os autores, pode existir efeito da estação do ano sobre a correlação provavelmente pela alteração da microbiota predominante (Gram-positiva e Gramnegativa).

\subsection{Conservação de amostras para determinação da contagem bacteriana através da metodologia de citometria de fluxo}

A utilização da citometria de fluxo permite a utilização de substâncias bacteriostáticas na conservação das amostras, uma vez que não existe a necessidade de crescimento bacteriano para a quantificação, como ocorre no método de referência.

A International Dairy Federation (International Dairy Federation, 1995), recomenda que amostras para determinação da CBT pelo método de referência devem ser mantidas a temperatura inferior a $4{ }^{\circ} \mathrm{C}$ e a análise realizada em até 48 horas após a coleta.

Para a determinação da CBT através da citometria de fluxo, autores recomendam a utilização da refrigeração associada a um conservante. Atualmente o conservante mais utilizado é o azidiol, que possui como princípio ativo o cloranfenicol e a azida sódica, ambos bacteriostáticos. Os autores citam que amostras refrigeradas e com azidiol 
poderiam ser analisadas em até quatro dias após a coleta (Barcina et al., 1987; Gonzalo et al., 2003; Ninane et al., 2000).

Fica evidente a vantagem da utilização de amostra conservada que possui uma maior vida útil. Tal fato é ainda mais importante no caso do Brasil em função do grande número de produtores e da extensão territorial, onde seria inviável a análise em até 48h.

Como grande parte das indústrias no Brasil realizam a coleta de leite na fazenda em dias alternados, seriam necessários dois dias para a realização da coleta de amostras de todos os seus fornecedores e mais um dia para transporte, sendo que a amostra seria recebida pelo laboratório no terceiro dia após a coleta. A amostra deveria portanto ser analisada pelo laboratório em no máximo um dia para respeitar a recomendação de quatro dias, meta esta dificilmente alcançada em função do grande número de amostras. Isto sugere que novos estudos devem ser conduzidos verificando a possibilidade de prolongar a vida útil da amostra.

No caso de amostras destinadas para a determinação da composição e da CCS, também se utiliza conservante, sendo o bronopol o mais utilizado (Bertrand et al., 1996; Meyer, 2003; Monardes et al., 1996; Van de Voort et al., 1987). Não existe na literatura trabalhos que utilizaram o bronopol como conservante para amostras de CBT, uma vez que o mesmo possui ação bactericida, o que degradaria as células bacterianas impossibilitando a identificação destas pelo equipamento.

Por outro lado, Gonzalo et al. (2003) verificaram decréscimo da CCS quando a amostra foi preservada com azidiol em relação à preservação com bronopol, mesmo utilizando refrigeração. Tais observações tornariam obrigatória a coleta de duas amostras de cada fazenda, uma destinada à determinação de CCS e composição, contendo bronopol e outra, para CBT, contendo azidiol. 


\section{CONSERVAÇÃO DE AMOSTRAS DE LEITE PARA DETERMINAÇÃO DA CONTAGEM BACTERIANA TOTAL PELO MÉTODO DE CITOMETRIA DE FLUXO}

\section{Resumo}

O objetivo do estudo foi avaliar o efeito da temperatura de armazenamento e da idade da amostra sobre a contagem bacteriana total (CBT), em amostras conservadas com azidiol. Também foi estudada a possibilidade de se utilizar uma única amostra de leite para a realização das análises previstas na Instrução Normativa 51 (IN-51). Para tanto foi coletado leite do tanque de expansão de uma fazenda e o mesmo foi distribuído em 320 frascos alocados num arranjo fatorial. Foram testadas três temperaturas de armazenamento $\left(0{ }^{\circ} \mathrm{C}\right.$ - congelado (C), $7{ }^{\circ} \mathrm{C}$ - resfriamento (R) e $24{ }^{\circ} \mathrm{C}$ - ambiente (A)), três conservantes (BR - bronopol, AZ - azidiol e SC - sem conservante) e quatro tempos entre a coleta e a análise (idade da amostra) (um (D1), três (D3), cinco (D5) e sete (D7) dias). Foi considerado tratamento controle para análise de CBT amostras refrigeradas, com azidiol, e com um dia de idade. Para as análises de composição e CCS, amostras refrigeradas, com bronopol e com um dia de idade, foram consideradas como tratamento controle. Amostras conservadas com bronopol tiveram uma CBT inferior ao tratamento controle independentemente da idade da amostra e da temperatura. Tal fato também foi observado para amostras conservadas com azidiol e armazenadas a $0{ }^{\circ} \mathrm{C}$. Já nas amostras armazenadas a $24{ }^{\circ} \mathrm{C}$ foi observado aumento da CBT independentemente da idade das amostras. As amostras que não receberam o azidiol apresentaram uma CBT superior a das amostras refrigeradas e conservadas com azidiol com um dia de idade. As amostras conservadas com azidiol e refrigeradas tiveram aumento linear na CBT de 
0,0058 log por dia, o que pode ser considerado pequeno e sem importância do ponto de vista aplicado. Amostras conservadas com o azidiol e refrigeradas apresentaram uma menor CCS, independentemente da idade da amostra, em relação a amostra refrigerada e preservada com o bronopol. Também foi observada redução nos teores de gordura e lactose após o D5. Para atender as análises previstas na IN-51, será necessária a coleta de duas amostras de cada fazenda, uma destinada à determinação de CCS e composição contendo o bronopol e, outra, para CBT, contendo azidiol. A amostra para CBT poderá ser analisada em até sete dias após a coleta se mantida sob refrigeração a $7^{\circ} \mathrm{C}$. Deve-se evitar o aquecimento ou congelamento da mesma, bem como garantir que o azidiol seja adicionado à amostra.

\section{PRESERVATION OF MILK SAMPLES FOR DETERMINATION OF TOTAL BACTERIAL COUNT USING FLOW CYTOMETRY}

\section{Summary}

The objective of this study was to evaluate the effect of storage temperature, sample age and milk preservative type on total bacterial count (TBC) of milk samples. Additionally, the use of a single milk sample to performance regulatory milk analysis under the Normative Instruction 51 (NI-51) was tested. Bulk milk from one farm was collected and split in 320 milk samples allocated in factorial arrangement. Effects were standardized as: three storage temperatures $\left(0^{\circ} \mathrm{C}-\right.$ freezer $(\mathrm{F}), 7^{\circ} \mathrm{C}-$ refrigerator $(\mathrm{R})$ and $24^{\circ} \mathrm{C}$ - room temperature (R)), four sample ages (1 (D1), 3 (D3), 5 (D5) and 7 (D7) days) and three milk preservatives (bronopol (B), azidiol (A) and no preservative (NP)). Control treatment for TBC analysis was defined as refrigerated milk samples containing azidiol with 1 day of storage. For determination of milk components and somatic cell count (SCC), control treatment was defined as refrigerated milk samples containing bronopol with 1 day of storage. Milk samples conserved with bronopol showed lower TBC as compared to milk samples from control treatment regardless storage temperature and sample age. The same result was observed for milk samples conserved with azidiol and stored at $0^{\circ} \mathrm{C}$. In opposition, milk samples stored at $24^{\circ} \mathrm{C}$ had high TBC regardless 
sample age. Milk samples without azidiol exhibited higher TBC as compared to refrigerated milk samples containing azidiol with 1 day of storage. Refrigerated milk samples containing azidiol showed a linear increase in TBC of 0.0058 log per day what can be considered derisory. Refrigerated milk samples containing azidiol demonstrated lower SCC, regardless sample age, compared to refrigerated milk samples containing bronopol. After D5, milk fat and protein showed reduction in percentage. Results of this study concluded that two bulk milk samples for each farm are necessary to performance regulatory milk analysis under the NI-51; one containing bronopol should be used for determination of milk components and SCC, and other containing azidiol for TBC. Milk samples used for TBC can be tested until 7 days after sampling if they are kept at $7^{\circ} \mathrm{C}$. Freezing or heating milk samples for TBC analysis should be avoided and addition of azidiol is always necessary.

\subsection{Introdução}

Um dos fatos mais importantes para o setor leiteiro nos últimos anos foi a aprovação da Instrução Normativa 51 (IN-51), do Ministério da Agricultura Pecuária e Abastecimento (MAPA), que determina novas variáveis de avaliação da qualidade do leite cru. De acordo com a IN-51, análises de contagem bacteriana total (CBT), contagem de células somáticas (CCS) e composição, de todo leite cru produzido no país e processado em estabelecimentos sob fiscalização federal, deverão ser realizadas mensalmente em um dos laboratórios credenciados pelo MAPA (BRASIL, 2002).

Para atender a demanda por estas análises, o MAPA criou a Rede Brasileira de Laboratórios de Análise da Qualidade do Leite (RBQL), composta atualmente por sete laboratórios centralizados que possuem equipamentos automatizados de última geração e de alto rendimento analítico.

A determinação da CBT será efetuada por meio do equipamento Bactocount (Bentley Instruments), o qual emprega a técnica de citometria de fluxo. Esta técnica consiste na adição de brometo de etídio (corante específico de DNA e RNA) ao leite, para que o DNA e RNA das bactérias sejam corados. O leite com o corante é injetado 
num capilar acoplado a um sistema óptico, que recebe, constantemente, um feixe de laser. Ao passar por este feixe, cada bactéria emite fluorescência, a qual é captada pelo sistema óptico (Barrientos et al., 2000; Broutin, 2004; Gunasekera et al., 2000; Suhren et al., 1999).

Esta nova metodologia analítica possibilita a utilização de conservantes bacteriostáticos que reduzem a atividade metabólica das bactérias, prolongando a vida útil da amostra destinada para tal análise. O conservante mais recomendado, atualmente, é o azidiol. Há citações na literatura de que amostras conservadas com azidiol podem ser analisadas em até quatro dias após a coleta, se mantidas sob refrigeração à $4^{\circ} \mathrm{C}$ (Barcina et al., 1987; Gonzalo et al., 2003; Ninane et al., 2000).

Em alguns países não se utiliza conservante, mas unicamente a refrigeração como mecanismo de preservação da amostra (Estados Unidos, 2001). Nestes casos, a distância entre as fazendas e os laboratórios são curtas, o que possibilita a análise em no máximo 48 horas após a coleta, como recomendado pela International Dairy Federation (International Dairy Federation, 1995).

No Brasil, em função do grande número de fazendas e da extensão territorial, torna-se inviável a coleta e análise em 48 horas, sendo necessária a utilização de conservantes no processo.

Atualmente utiliza-se o bronopol para a conservação de amostras destinadas às análises de composição e de CCS (Bertrand et al., 1996; Meyer, 2003; Monardes et al., 1996; Van de Voort et al., 1987). Não existem na literatura trabalhos que utilizaram o bronopol como conservante para amostras de CBT, uma vez que o mesmo possui ação bactericida, o que degradaria as células bacterianas impossibilitando a sua identificação pelo equipamento. Por outro lado, foi verificado decréscimo da CCS, quando a amostra foi conservada com azidiol em relação à preservação com bronopol, mesmo utilizando a refrigeração (Gonzalo et al., 2003). Tais observações tornariam obrigatória a coleta de duas amostras de cada fazenda, uma destinada à determinação de CCS e composição contendo o bronopol e, outra, para CBT, contendo azidiol.

O presente trabalho teve como objetivo, verificar a possibilidade de utilizar uma única amostra conservada com azidiol para determinação das análises previstas na IN- 
51, o que reduziria custos com material de coleta e transporte. Além disso, verificar os efeitos da temperatura de armazenamento e a idade da amostra sobre a CBT.

\subsection{Material e Métodos}

\subsubsection{Coleta do leite}

O leite utilizado no experimento foi coletado do tanque de expansão do rebanho leiteiro do Departamento de Zootecnia da Escola Superior de Agricultura "Luiz de Queiroz”, Universidade de São Paulo. O leite foi homogeneizado acionando-se o agitador do tanque durante cinco minutos. Após este período, o leite foi transferido, com auxílio de uma concha, para um galão limpo e seco e encaminhado para o laboratório da Clínica do Leite do Departamento de Zootecnia, da Escola Superior de Agricultura “Luiz de Queiroz”, Universidade de São Paulo.

O leite foi transferido para 320 frascos plásticos esterilizados, com $50 \mathrm{~mL}$ de capacidade. Os frascos foram alocados num arranjo fatorial (4 tempos de análise $\times 3$ conservantes $\times 3$ temperaturas). Foram utilizados dez frascos para cada tratamento.

\subsubsection{Conservantes}

Foram testadas três situações: adição de bronopol (BR), de azidiol (AZ) e sem adição conservante (SC) na amostra.

O bronopol, em forma de pastilha, foi adquirido da empresa D\&F Control (Microtabs II). Cada pastilha possui $8 \mathrm{mg}$ de bronopol (2-bromo-2-nitropropano-1,3diol) e 0,3 mg de natamicima, um agente antifúngico. Utilizou-se uma pastilha para cada $50 \mathrm{~mL}$ de leite.

A solução de azidiol foi preparada de acordo com Barcina et al. (1987), contendo 0,15 \% de cloranfenicol e 3,6 \% de azida sódica. Foram utilizadas quatro gotas (160 uL) da solução para cada $50 \mathrm{~mL}$ de leite. 


\subsubsection{Temperatura de armazenamento}

Foram testadas três temperaturas de armazenamento: congelamento a $0{ }^{\circ} \mathrm{C}(\mathrm{C})$, resfriamento a $7{ }^{\circ} \mathrm{C}(\mathrm{R})$ e temperatura ambiente a $24{ }^{\circ} \mathrm{C}(\mathrm{A})$.

Para amostras SC foram testadas apenas duas temperaturas de armazenamento (C e R), uma vez que amostras sem conservantes e a temperatura ambiente degradam rapidamente, devido ao rápido crescimento bacteriano.

\subsubsection{Tempo entre a coleta e a análise}

Foram testados quatro tempos entre a coleta e a análise (idade da amostra): um (D1), três (D3), cinco (D5) e sete (D7) dias.

\subsubsection{Análise laboratorial}

As amostras foram analisadas nos equipamentos Bactocount (Bentley Instruments, 2004), Bentley 2000 (Bentley Instruments, 1995a) e Somacount 300 (Bentley Instruments, 1995b) para determinação da CBT, composição e CCS, respectivamente. Os equipamentos Bactocount e Somacount utilizam a metodologia de citometria de fluxo e o Bentley 2000 emprega a metodologia de absorção infravermelha.

\subsubsection{Análise estatística}

Os dados foram analisados usando o procedimento PROC GLM do SAS (1999). A análise de variância foi realizada considerando-se os efeitos de conservante, temperatura, idade das amostras e suas interações. No desdobramento da análise estatística foi utilizado o teste de Tukey para os efeitos de conservante e de temperatura, e a análise de regressão, para idade das amostras.

A CCS (x $10^{3}$ células $/ \mathrm{mL}$ ) foi transformada em logaritmo natural (LCCS) e a CBT (x $10^{3} \mathrm{UFC} / \mathrm{mL}$ ) transformada em logaritmo na base 10. 


\subsection{Resultados e Discussão}

O conservante bronopol é amplamente utilizado na conservação das amostras destinadas à análise de composição e de CCS. Além do conservante, autores citam a importância da refrigeração e da realização da análise em no máximo três dias após a coleta das amostras como fatores adicionais para manutenção da integridade da amostra e obtenção de resultados confiáveis (Bertrand et al., 1996; Meyer, 2003; Monardes et al., 1996; Van de Voort et al., 1987). No presente estudo, considerou-se tratamento controle para as variáveis, gordura, proteína, lactose, sólidos totais e CCS, amostras conservadas com bronopol (BR), armazenadas a $7{ }^{\circ} \mathrm{C}(\mathrm{R})$ e analisadas com um dia após a coleta (D1). No caso da CBT, considerou-se tratamento controle amostras conservadas com azidiol (AZ), armazenadas a $7{ }^{\circ} \mathrm{C}(\mathrm{R})$ e analisadas com um dia após a coleta (D1), uma vez que trabalhos citam a utilização deste procedimento na conservação de amostras para estes fins (Barcina et al., 1987; Gonzalo et al., 2003; Ninane et al., 2000).

A análise de variância considerando os efeitos de conservante, temperatura, idade da amostra e suas interações é apresentada na Tabela 1. 
Tabela 1. Análise de variância considerando os efeitos de conservante, temperatura, idade da amostra e suas interações

\begin{tabular}{lccccccc}
\hline Causas de Variação & GL & log CBT * & Gordura ** & Proteína & Lactose & $\begin{array}{c}\text { Sólidos } \\
\text { Totais }\end{array}$ & CCS *** \\
\hline Conservante (C) & 2 & $<, 0001$ & $<, 0001$ & $<, 0001$ & $<, 0001$ & $<, 0001$ & $<, 0001$ \\
Temperatura (T) & 2 & $<, 0001$ & 0,0006 & $<, 0001$ & $<, 0001$ & 0,0018 & $<, 0001$ \\
Idade (I) & 3 & $<, 0001$ & $<, 0001$ & $<, 0001$ & $<, 0001$ & $<, 0001$ & $<, 0001$ \\
C x T & 3 & $<, 0001$ & $<, 0001$ & $<, 0001$ & $<, 0001$ & 0,1724 & $<, 0001$ \\
C x I & 6 & $<, 0001$ & 0,0580 & $<, 0001$ & $<, 0001$ & 0,2695 & 0,1168 \\
T x I & 6 & $<, 0001$ & 0,0164 & $<, 0001$ & $<, 0001$ & 0,1532 & $<, 0001$ \\
C x T x I & 9 & $<, 0001$ & 0,4639 & $<, 0001$ & $<, 0001$ & 0,0019 & $<, 0001$ \\
\hline * Val
\end{tabular}

* Valores transformados em logaritmo na base 10 ;

** Análise da variância ponderada pelo inverso da variância dos níveis de temperatura;

*** Valores transformados em logaritmo na base natural e análise da variância ponderada pelo inverso da variância dos níveis de conservante e idade das amostras.

Nota-se que a maioria dos efeitos foram significativos, com exceção para a gordura (Conservante $\times$ Idade e Conservante $\times$ Temperatura $\times$ Idade), sólidos totais (Conservante $\times$ Temperatura, Conservante $\times$ Idade e Temperatura $\times$ Idade) e contagem de células somáticas (Conservante $\times$ Idade). A interação tripla foi significativa para todas as variáveis, exceto para gordura, e então optou-se por analisar a interação tripla para todas as variáveis.

Verificou-se que pela análise das médias do logaritmo da CBT $\left(10^{3} \mathrm{ufc} / \mathrm{mL}\right)$, que amostras conservadas com bronopol tiveram uma CBT inferior ao tratamento controle independentemente da idade das amostras e da temperatura de conservação (Tabela 2). 
Tabela 2. Médias e erros padrões do logaritmo da CBT em função do conservante, da temperatura e da idade das amostras

\begin{tabular}{|c|c|c|c|}
\hline \multirow{2}{*}{ Temperatura $\left({ }^{\circ} \mathrm{C}\right)$} & \multicolumn{3}{|c|}{ Conservante } \\
\hline & Sem & Azidiol & Bronopol \\
\hline & & Amostra de 1 dia & \\
\hline 0 & $2,17 \pm, 023^{\mathrm{bA}}$ & $2,14 \pm, 004^{\mathrm{cAB}}$ & $2,09 \pm, 006^{\mathrm{aB}}$ \\
\hline 7 & $2,53 \pm, 018^{\mathrm{aA}}$ & $2,21 \pm, 004^{\mathrm{bB}}$ & $2,09 \pm, 005^{\mathrm{aC}}$ \\
\hline 24 & & $2,39 \pm, 006^{\mathrm{aA}}$ & $2,05 \pm, 003^{\mathrm{aB}}$ \\
\hline & & Amostra de 3 dias & \\
\hline 0 & $2,17 \pm, 005^{\mathrm{bA}}$ & $2,14 \pm, 004^{\mathrm{cA}}$ & $2,08 \pm, 004^{\mathrm{aB}}$ \\
\hline 7 & $3,09 \pm, 023^{\text {aA }}$ & $2,22 \pm, 005^{\mathrm{bB}}$ & $2,07 \pm, 006^{\mathrm{aC}}$ \\
\hline 24 & & $2,45 \pm, 008^{\mathrm{aA}}$ & $2,01 \pm, 005^{b B}$ \\
\hline & & Amostra de 5 dias & \\
\hline 0 & $2,17 \pm, 003^{\mathrm{bA}}$ & $2,15 \pm, 006^{\mathrm{cAB}}$ & $2,10 \pm, 006^{\mathrm{aB}}$ \\
\hline 7 & $3,28 \pm, 007^{\mathrm{aA}}$ & $2,23 \pm, 011^{\mathrm{bB}}$ & $2,07 \pm, 006^{\mathrm{aC}}$ \\
\hline 24 & & $2,68 \pm, 022^{\mathrm{aA}}$ & $2,01 \pm, 013^{\mathrm{bB}}$ \\
\hline & & Amostra de 7 dias & \\
\hline 0 & $2,14 \pm, 006^{\mathrm{bA}}$ & $2,13 \pm, 003^{\mathrm{cA}}$ & $2,09 \pm, 004^{\mathrm{aA}}$ \\
\hline 7 & $3,30 \pm, 003^{\mathrm{aA}}$ & $2,25 \pm, 007^{\mathrm{bB}}$ & $2,05 \pm, 005^{\mathrm{aC}}$ \\
\hline 24 & & $2,98 \pm, 024^{\mathrm{aA}}$ & $1,99 \pm, 009^{\mathrm{bB}}$ \\
\hline
\end{tabular}

Médias seguidas por letras maiúsculas nas linhas diferem entre si pelo teste de Tukey $(\mathrm{p} \leq 0,05)$;

Médias seguidas por letras minúsculas nas colunas diferem entre si pelo teste de Tukey ( $\leq \leq 0,05)$, dentro da idade.

Tal fato pode ser explicado pela ação bactericida do bronopol, que provoca danos às células bacterianas que não são mais identificadas pelo sistema óptico do equipamento, não sendo recomendável a sua utilização em amostras destinadas à análise de CBT.

Da mesma forma, amostras conservadas com azidiol e congeladas (C), apresentaram menor CBT em relação às amostras refrigeradas (R) independentemente da idade da amostra. Sabe-se que o congelamento pode provocar injúrias nas células bacterianas e que também não são identificadas. Tal observação sugere que as amostras destinadas para a análise não podem sofrer congelamento durante o transporte até o laboratório, fato esse comumente observado pela utilização em excesso de gelo químico nas caixas térmicas utilizadas para transporte. A quantidade de gelo a ser utilizada deve ser dimensionada em função do tamanho da caixa térmica e da quantidade de amostras a serem transportadas. 
Por outro lado, amostras conservadas com azidiol e mantidas a temperatura ambiente (A) apresentaram uma maior CBT independentemente da idade da amostra. Como já citado por outros autores, tal fato demonstra a importância da refrigeração na conservação das amostras, uma vez que somente a utilização do conservante não foi suficiente para cessar o crescimento bacteriano.

Os resultados de CBT obtidos para amostras congeladas (C) e mantidas a temperatura ambiente (A) ressaltam a importância de se manter a temperatura de resfriamento constante durante o transporte das amostras, evitando-se o congelamento ou o aquecimento.

As amostras que não receberam o azidiol (SC) apresentaram uma CBT superior a das amostras refrigeradas (R) com um dia de idade, mesmo quando mantidas sobrefrigeração. Somente a refrigeração pode ser utilizada na conservação de amostras, desde que a temperatura não ultrapasse $4{ }^{\circ} \mathrm{C}$ (International Dairy Federation, 1995). Portanto, é fundamental garantir que as amostras resfriadas a temperaturas superiores, como utilizado neste estudo, recebam o conservante. Seria interessante que os laboratórios disponibilizassem os frascos para coleta, já contendo a solução de azidiol na quantidade adequada. Esta solução por sua vez, deveria conter corante como indicador da sua presença na amostra.

Já as amostras conservadas com azidiol e refrigeradas tiveram aumento linear na CBT ao longo do tempo (Figura 1). O aumento foi de 0,0058 log por dia, ou 2,17 x $10^{3}$ ufc/mL que pode ser considerado pequeno e sem importância do ponto de vista aplicado. Os planos de pagamento por qualidade propostos pelas indústrias, estabelecem classes de pagamento com amplitude variando de 20 a $650 \mathrm{mil}$ ufc/mL, e o aumento diário observado não resultaria em mudança de classe de pagamento.

Autores sugerem que amostra com azidiol e refrigerada, poderia ser analisada em até quatro dias após a coleta (Barcina et al., 1987; Gonzalo et al., 2003; Ninane et al., 2000). No presente trabalho observou-se que poderia ser utilizado um período maior, de até sete dias. 


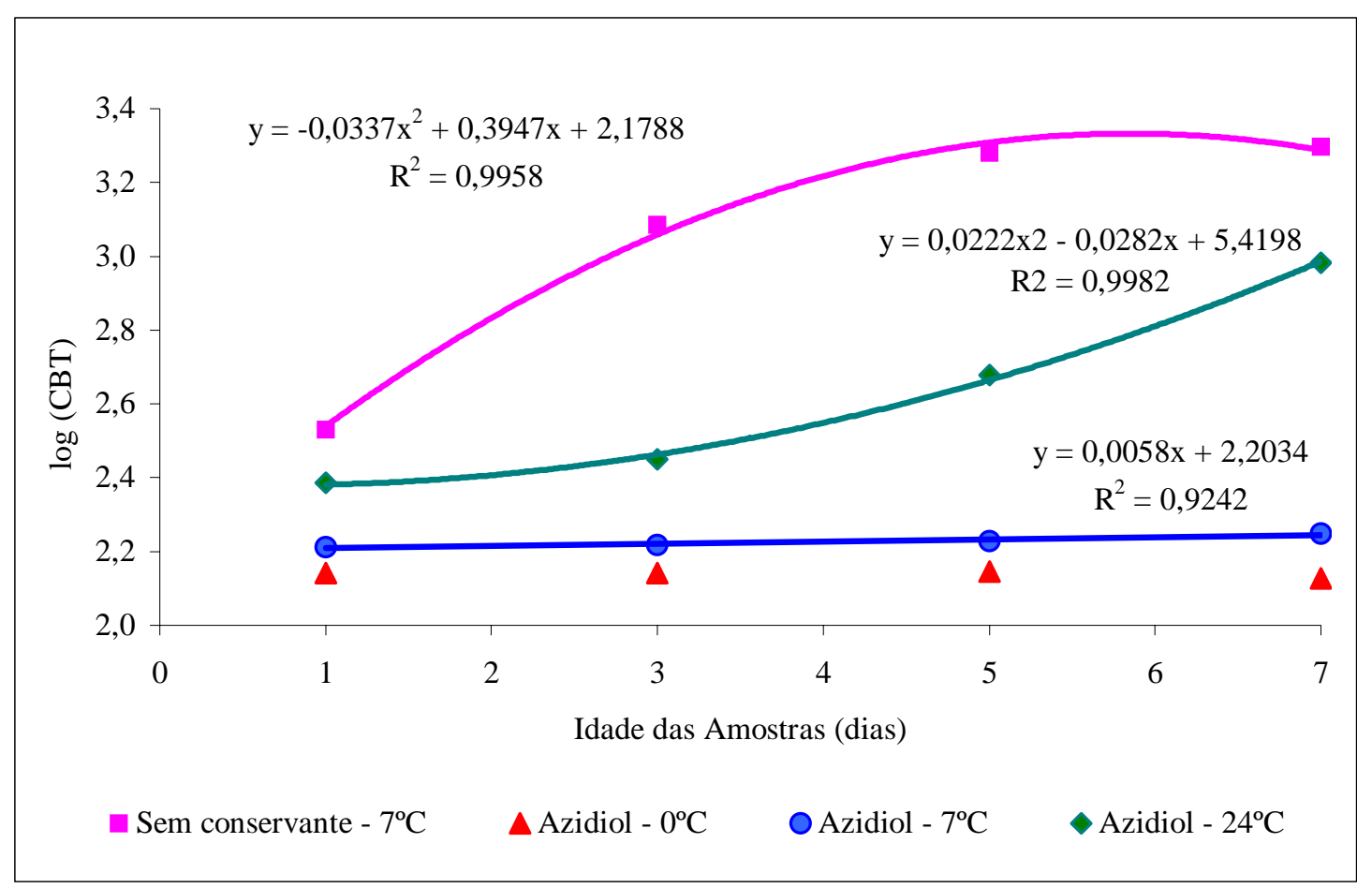

Figura 1- Contagem bacteriana total em função da temperatura de armazenamento e da idade das amostras

Com base nos resultados obtidos, sugere-se que, para amostras destinadas a análise de CBT, seja utilizado o conservante azidiol em associação com a refrigeração. No entanto, observando os resultados na Tabela 4, nota-se que esta mesma amostra não poderia ser utilizada para a análise de CCS. Amostras conservadas com azidiol e refrigeradas (R) tiveram uma menor CCS em relação às amostras conservadas com bronopol, independentemente da idade da amostra. Tal fato também foi observado por Gonzalo et al. (2003). 
Tabela 4. Médias e erros padrões do logaritmo natural da CCS em função do conservante, da temperatura e da idade das amostras

\begin{tabular}{|c|c|c|c|}
\hline \multirow{2}{*}{ Temperatura $\left({ }^{\circ} \mathrm{C}\right)$} & \multicolumn{3}{|c|}{ Conservante } \\
\hline & Sem & Azidiol & Bronopol \\
\hline & & Amostra de 1 dia & \\
\hline 0 & $6,73 \pm, 023^{\mathrm{aB}}$ & $6,60 \pm, 010^{\mathrm{aC}}$ & $6,80 \pm, 007^{\mathrm{bA}}$ \\
\hline 7 & $6,67 \pm, 009^{\mathrm{bB}}$ & $6,54 \pm, 008^{\mathrm{aC}}$ & $6,84 \pm, 006^{\mathrm{aA}}$ \\
\hline 24 & & $6,43 \pm, 010^{\mathrm{bB}}$ & $6,83 \pm, 006^{\mathrm{aA}}$ \\
\hline & & Amostra de 3 dias & \\
\hline 0 & $6,68 \pm, 004^{\mathrm{bB}}$ & $6,64 \pm, 011^{\mathrm{aB}}$ & $6,77 \pm, 003^{\mathrm{bA}}$ \\
\hline 7 & $6,76 \pm, 008^{\mathrm{aB}}$ & $6,59 \pm, 004^{\mathrm{aC}}$ & $6,84 \pm, 004^{\mathrm{aA}}$ \\
\hline 24 & & $6,14 \pm, 009^{\mathrm{bB}}$ & $6,76 \pm, 004^{\mathrm{bA}}$ \\
\hline & & Amostra de 5 dias & \\
\hline 0 & $6,64 \pm, 035^{\mathrm{aA}}$ & $6,57 \pm, 010^{\mathrm{aA}}$ & $6,72 \pm, 005^{\mathrm{aA}}$ \\
\hline 7 & $6,61 \pm, 027^{\mathrm{aB}}$ & $6,48 \pm, 006^{\mathrm{aB}}$ & $6,75 \pm, 009^{\mathrm{aA}}$ \\
\hline 24 & & $5,81 \pm, 008^{\mathrm{bB}}$ & $6,50 \pm, 010^{\mathrm{bA}}$ \\
\hline & & Amostra de 7 dias & \\
\hline 0 & $6,61 \pm, 018^{\mathrm{aA}}$ & $6,51 \pm, 009^{\mathrm{aA}}$ & $6,67 \pm, 004^{\mathrm{aA}}$ \\
\hline 7 & $6,55 \pm, 007^{\mathrm{bB}}$ & $6,46 \pm, 007^{\mathrm{aB}}$ & $6,68 \pm, 004^{\mathrm{aA}}$ \\
\hline 24 & & $5,59 \pm, 012^{\mathrm{bB}}$ & $6,27 \pm, 009^{\mathrm{bA}}$ \\
\hline
\end{tabular}

Médias seguidas por letras maiúsculas nas linhas diferem entre si pelo teste de Tukey $(\mathrm{p} \leq 0,05)$;

Médias seguidas por letras minúsculas nas colunas diferem entre si pelo teste de Tukey ( $\leq \leq 0,05)$, dentro da idade.

Também foi observada uma redução nos teores de gordura e lactose, a partir do D5 como pode ser visto nas Tabelas 5 e 6, para amostras conservadas com azidiol e refrigeradas em relação a amostra com bronopol sob a mesma temperatura. Não foram encontrados trabalhos na literatura que citem esta redução nos teores em função da utilização do azidiol em substituição ao bronopol. 
Tabela 5. Médias e erros padrões da \% de gordura em função do conservante, da temperatura e da idade das amostras

\begin{tabular}{|c|c|c|c|}
\hline \multirow[b]{2}{*}{ Temperatura $\left({ }^{\circ} \mathrm{C}\right)$} & \multicolumn{3}{|c|}{ Conservante } \\
\hline & Sem & Azidiol & Bronopol \\
\hline & & Amostra de 1 dia & \\
\hline 0 & $3,63 \pm, 004^{\mathrm{aA}}$ & $3,60 \pm, 008^{\mathrm{aB}}$ & $3,61 \pm, 006^{\mathrm{aAB}}$ \\
\hline 7 & $3,62 \pm, 002^{\mathrm{aA}}$ & $3,60 \pm, 001^{\mathrm{aA}}$ & $3,62 \pm, 002^{\mathrm{aA}}$ \\
\hline 24 & & $3,60 \pm, 005^{\mathrm{aA}}$ & $3,61 \pm, 002^{\mathrm{aA}}$ \\
\hline & & Amostra de 3 dias & \\
\hline 0 & $3,63 \pm, 002^{\mathrm{aA}}$ & $3,60 \pm, 005^{\mathrm{aB}}$ & $3,61 \pm, 003^{\mathrm{aAB}}$ \\
\hline 7 & $3,63 \pm, 002^{\mathrm{aA}}$ & $3,62 \pm, 002^{\mathrm{aA}}$ & $3,63 \pm, 002^{\mathrm{aA}}$ \\
\hline 24 & & $3,60 \pm, 003^{\mathrm{aA}}$ & $3,62 \pm, 003^{\mathrm{aA}}$ \\
\hline & & Amostra de 5 dias & \\
\hline 0 & $3,65 \pm, 004^{\mathrm{aA}}$ & $3,62 \pm, 005^{\mathrm{aB}}$ & $3,62 \pm, 004^{\mathrm{aB}}$ \\
\hline 7 & $3,63 \pm, 003^{\mathrm{aA}}$ & $3,61 \pm, 003^{\mathrm{aB}}$ & $3,63 \pm, 001^{\mathrm{aA}}$ \\
\hline 24 & & $3,61 \pm, 008^{\mathrm{aA}}$ & $3,62 \pm, 003^{\mathrm{aA}}$ \\
\hline & & Amostra de 7 dias & \\
\hline 0 & $3,65 \pm, 002^{\mathrm{aA}}$ & $3,63 \pm, 002^{\mathrm{aA}}$ & $3,63 \pm, 003^{\mathrm{abA}}$ \\
\hline 7 & $3,64 \pm, 005^{\mathrm{aA}}$ & $3,62 \pm, 002^{\mathrm{aB}}$ & $3,64 \pm, 001^{\mathrm{aA}}$ \\
\hline 24 & & $3,62 \pm, 002^{\mathrm{aA}}$ & $3,61 \pm, 009^{\mathrm{bA}}$ \\
\hline
\end{tabular}

Médias seguidas por letras maiúsculas nas linhas diferem entre si pelo teste de Tukey $(\mathrm{p} \leq 0,05)$;

Médias seguidas por letras minúsculas nas colunas diferem entre si pelo teste de Tukey $(p \leq 0,05)$, dentro de da idade. 
Tabela 6. Médias e erros padrões das \% de lactose em função do conservante, da temperatura e da idade das amostras

\begin{tabular}{|c|c|c|c|}
\hline \multirow{2}{*}{ Temperatura $\left({ }^{\circ} \mathrm{C}\right)$} & \multicolumn{3}{|c|}{ Conservante } \\
\hline & Sem & Azidiol & Bronopol \\
\hline & & Amostra de 1 dia & \\
\hline 0 & $4,17 \pm, 018^{\mathrm{bB}}$ & $4,18 \pm, 009^{\mathrm{bB}}$ & $4,22 \pm, 003^{\mathrm{aA}}$ \\
\hline 7 & $4,22 \pm, 001^{\mathrm{aA}}$ & $4,20 \pm, 001^{\mathrm{aA}}$ & $4,22 \pm, 001^{\mathrm{aA}}$ \\
\hline \multirow[t]{2}{*}{24} & & $4,21 \pm, 002^{\mathrm{aB}}$ & $4,23 \pm, 001^{\mathrm{aA}}$ \\
\hline & & Amostra de 3 dias & \\
\hline 0 & $4,21 \pm, 002^{\mathrm{aAB}}$ & $4,20 \pm, 001^{\mathrm{aB}}$ & $4,23 \pm, 002^{\mathrm{aA}}$ \\
\hline 7 & $4,21 \pm, 002^{\mathrm{aAB}}$ & $4,22 \pm, 002^{\mathrm{aA}}$ & $4,23 \pm, 001^{\mathrm{aA}}$ \\
\hline \multirow[t]{2}{*}{24} & & $4,21 \pm, 002^{\mathrm{aA}}$ & $4,23 \pm, 002^{\mathrm{aA}}$ \\
\hline & & Amostra de 5 dias & \\
\hline 0 & $4,19 \pm, 003^{\mathrm{aB}}$ & $4,17 \pm, 002^{\mathrm{bB}}$ & $4,22 \pm, 004^{\mathrm{aA}}$ \\
\hline 7 & $4,18 \pm, 003^{\mathrm{aB}}$ & $4,20 \pm, 002^{\mathrm{aB}}$ & $4,23 \pm, 001^{\mathrm{aA}}$ \\
\hline \multirow[t]{2}{*}{24} & & $4,21 \pm, 002^{\mathrm{aB}}$ & $4,23 \pm, 001^{\mathrm{aA}}$ \\
\hline & & Amostra de 7 dias & \\
\hline 0 & $4,19 \pm, 002^{\mathrm{aAB}}$ & $4,17 \pm, 001^{\mathrm{aB}}$ & $4,20 \pm, 002^{\mathrm{aA}}$ \\
\hline 7 & $4,13 \pm, 005^{\mathrm{bC}}$ & $4,19 \pm, 002^{\mathrm{aB}}$ & $4,21 \pm, 000^{\mathrm{aA}}$ \\
\hline 24 & & $4,18 \pm, 001^{\mathrm{aB}}$ & $4,21 \pm, 002^{\mathrm{aA}}$ \\
\hline \multicolumn{4}{|c|}{$\begin{array}{l}\text { Médias seguidas por letras maiúsculas nas linhas diferem entre si pelo teste de Tukey }(\mathrm{p} \leq 0,05) ; \\
\text { Médias seguidas por letras minúsculas nas colunas diferem entre si pelo teste de Tukey }(\mathrm{p} \leq 0,05) \text {, dentro da idade. }\end{array}$} \\
\hline \multicolumn{4}{|c|}{ O mesmo não ocorreu com os teores de proteína e sólidos totais (Tabela 7 e 8} \\
\hline
\end{tabular}


Tabela 7. Médias e erros padrões da \% de proteína em função do conservante, da temperatura e da idade das amostras

\begin{tabular}{|c|c|c|c|}
\hline \multirow{2}{*}{ Temperatura $\left({ }^{\circ} \mathrm{C}\right)$} & \multicolumn{3}{|c|}{ Conservante } \\
\hline & Sem & Azidiol & Bronopol \\
\hline & & Amostra de 1 dia & \\
\hline 0 & $2,98 \pm, 012^{\mathrm{aA}}$ & $2,99 \pm, 005^{\mathrm{aA}}$ & $2,98 \pm, 002^{\mathrm{aA}}$ \\
\hline 7 & $2,97 \pm, 002^{\mathrm{aA}}$ & $2,98 \pm, 002^{\mathrm{aA}}$ & $2,98 \pm, 001^{\mathrm{aA}}$ \\
\hline 24 & & $2,98 \pm, 001^{\mathrm{aA}}$ & $2,98 \pm, 001^{\mathrm{aA}}$ \\
\hline & & Amostra de 3 dias & \\
\hline 0 & $3,01 \pm, 002^{\mathrm{aA}}$ & $3,02 \pm, 002^{\mathrm{aA}}$ & $3,01 \pm, 002^{\mathrm{aA}}$ \\
\hline 7 & $3,01 \pm, 000^{\text {aA }}$ & $3,02 \pm, 002^{\text {aA }}$ & $3,02 \pm, 002^{\mathrm{aA}}$ \\
\hline 24 & & $3,02 \pm, 003^{\mathrm{aA}}$ & $3,02 \pm, 002^{\mathrm{aA}}$ \\
\hline & & Amostra de 5 dias & \\
\hline 0 & $3,03 \pm, 001^{\mathrm{aA}}$ & $3,04 \pm, 002^{\mathrm{aA}}$ & $3,03 \pm, 004^{\mathrm{aA}}$ \\
\hline 7 & $3,04 \pm, 003^{\mathrm{aA}}$ & $3,02 \pm, 003^{\mathrm{bA}}$ & $3,02 \pm, 001^{\mathrm{aA}}$ \\
\hline 24 & & $3,04 \pm, 002^{\mathrm{abA}}$ & $3,02 \pm, 002^{\mathrm{aA}}$ \\
\hline & & Amostra de 7 dias & \\
\hline 0 & $3,03 \pm, 002^{\mathrm{bA}}$ & $3,04 \pm, 002^{\mathrm{bA}}$ & $3,03 \pm, 002^{\mathrm{bA}}$ \\
\hline 7 & $3,07 \pm, 003^{\mathrm{aA}}$ & $3,04 \pm, 001^{\mathrm{bB}}$ & $3,04 \pm, 002^{a b B}$ \\
\hline 24 & & $3,06 \pm, 001^{\mathrm{aA}}$ & $3,04 \pm, 002^{\mathrm{aB}}$ \\
\hline
\end{tabular}

Médias seguidas por letras maiúsculas nas linhas diferem entre si pelo teste de Tukey $(\mathrm{p} \leq 0,05)$;

Médias seguidas por letras minúsculas nas colunas diferem entre si pelo teste de Tukey $(p \leq 0,05)$, dentro de da idade. 
Tabela 8. Médias e erros padrões da \% de sólidos totais em função do conservante, da temperatura e da idade das amostras

\begin{tabular}{|c|c|c|c|}
\hline \multirow{2}{*}{ Temperatura $\left({ }^{\circ} \mathrm{C}\right)$} & \multicolumn{3}{|c|}{ Conservante } \\
\hline & Sem & Azidiol & Bronopol \\
\hline & & Amostra de 1 dia & \\
\hline 0 & $11,65 \pm, 062^{\mathrm{bB}}$ & $11,66 \pm, 025^{\mathrm{aAB}}$ & $11,73 \pm, 004^{\mathrm{aA}}$ \\
\hline 7 & $11,73 \pm, 003^{\mathrm{aA}}$ & $11,69 \pm, 002^{\mathrm{aA}}$ & $11,74 \pm, 002^{\mathrm{aA}}$ \\
\hline 24 & & $11,70 \pm, 006^{\mathrm{aA}}$ & $11,74 \pm, 002^{\mathrm{aA}}$ \\
\hline & & Amostra de 3 dias & \\
\hline 0 & $11,76 \pm, 004^{\mathrm{aA}}$ & $11,72 \pm, 006^{\mathrm{aA}}$ & $11,77 \pm, 005^{\mathrm{aA}}$ \\
\hline 7 & $11,77 \pm, 002^{\mathrm{aA}}$ & $11,73 \pm, 002^{\mathrm{aA}}$ & $11,79 \pm, 003^{\mathrm{aA}}$ \\
\hline 24 & & $11,75 \pm, 004^{\mathrm{aA}}$ & $11,79 \pm, 003^{\mathrm{aA}}$ \\
\hline & & Amostra de 5 dias & \\
\hline 0 & $11,76 \pm, 004^{\mathrm{aA}}$ & $11,72 \pm, 004^{\mathrm{aA}}$ & $11,78 \pm, 008^{\mathrm{aA}}$ \\
\hline 7 & $11,74 \pm, 004^{\mathrm{aA}}$ & $11,74 \pm, 003^{\mathrm{aA}}$ & $11,80 \pm, 002^{\mathrm{aA}}$ \\
\hline 24 & & $11,75 \pm, 008^{\mathrm{aA}}$ & $11,79 \pm, 004^{\mathrm{aA}}$ \\
\hline & & Amostra de 7 dias & \\
\hline 0 & $11,76 \pm, 003^{\mathrm{aA}}$ & $11,73 \pm, 003^{\mathrm{aA}}$ & $11,75 \pm, 006^{\mathrm{aA}}$ \\
\hline 7 & $11,70 \pm, 008^{\mathrm{aB}}$ & $11,74 \pm, 003^{\text {аАВ }}$ & $11,80 \pm, 003^{\mathrm{aA}}$ \\
\hline 24 & & $11,75 \pm, 003^{\mathrm{aA}}$ & $11,78 \pm, 010^{\mathrm{aA}}$ \\
\hline
\end{tabular}

Médias seguidas por letras maiúsculas nas linhas diferem entre si pelo teste de Tukey $(\mathrm{p} \leq 0,05)$;

Médias seguidas por letras minúsculas nas colunas diferem entre si pelo teste de Tukey $(p \leq 0,05)$, dentro de da idade.

Por meio dos resultados obtidos, observou-se que os teores de gordura, proteína, lactose, sólidos totais e a CCS foram semelhantes até sete dias após a coleta quando as amostras foram conservadas com bronopol, independentemente da temperatura de armazenamento. Tal fato também foi observado por Meyer (2003), que utilizou temperaturas de armazenamento semelhantes. As amostras destinadas para as análises de composição e CCS conservadas com bronopol e mantidas sob refrigeração podem ser analisadas em até sete dias, assim como a amostra destinada para CBT conservada com azidiol e refrigerada.

No entanto, as reduções observadas na CCS, gordura e lactose, inviabilizam a utilização de uma única amostra conservada com azidiol e refrigerada, para a realização de todas as análises exigidas pela IN-51. 


\subsection{Conclusão}

Para atender as análises previstas na IN-51 será necessária a coleta de duas amostras de cada fazenda, uma destinada à determinação de CCS e composição, contendo o bronopol e, outra, para CBT, contendo azidiol.

A amostra para CBT poderá ser analisada em até sete dias após a coleta desde que mantida sob refrigeração a $7{ }^{\circ} \mathrm{C}$. Deve-se evitar o aquecimento ou congelamento da mesma, bem como garantir que à amostra seja adicionado o azidiol. 


\section{CORRELAÇÃO ENTRE OS MÉTODOS DE REFERÊNCIA E DE CITOMETRIA DE FLUXO PARA DETERMINAÇÃO DA CONTAGEM BACTERIANA TOTAL NO LEITE CRU}

\section{Resumo}

O objetivo do estudo foi estabelecer a correlação entre os métodos de referência e de citometria de fluxo na determinação da contagem bacteriana total do leite. O efeito da época do ano sobre a correlação também foi estudado. Foram coletadas 223 amostras de leite de produtores dos estados de Minas Gerais e São Paulo, durante os meses de junho a dezembro de 2004. Amostras coletadas nos meses de junho a setembro foram agrupadas considerando-se estação da seca e amostras coletadas nos meses de novembro e dezembro, estação das águas. Foram realizadas análises simultâneas pelos métodos de referência (contagem padrão em placas) e de citometria de fluxo (equipamento Bactocount Bentley Instruments), sendo os resultados expressos em unidades formadoras de colônia (UFC) e contagem individual de bactérias (CIB), respectivamente. As equações lineares de correlação entre a CIB e UFC foram semelhantes nas estações, indicando que uma única equação de correlação pode ser utilizada ao longo do ano para transformar os resultados de CIB em UFC. A equação linear de regressão obtida foi: $\log (\mathrm{UFC})=\log (\mathrm{CIB})$ x $0,7224+1,4617$ com coeficiente de correlação de 0,8125. A acurácia do equipamento Bactocount na estimativa do valor de referência, expressa pelo erro padrão $(\mathrm{s}(\mathrm{y}, \mathrm{x})$ ), foi de 0,309 log UFC/mL. O equipamento Bactocount pode ser calibrado para expressar os resultados em UFC e com isso ser utilizado como método alternativo no monitoramento da qualidade do leite no país. 


\section{CORRELATION BETWEEN STANDARD PLATE COUNT AND FLOW CYTOMETRY FOR DETERMINATION OF RAW MILK TOTAL BACTERIAL COUNT}

\section{Summary}

The objective of this study was to establish a correlation between electronic flow cytometry and standard plate count for determination of total bacterial count of raw milk. Additionally, the effect of season on the correlation was verified. A total of 223 bulk milk samples were collected from dairies of São Paulo and Minas Gerais state from June to December of 2004. Milk samples collected from June to September $(n=155)$ were named as dry season samples and milk samples collected in November and December $(n=68)$ were named as rainy season samples. Each milk sample was used to run both methods of total bacterial count. Results were expressed as individual bacterial count (IBC) and colony forming unit (CFU) for electronic flow cytometry (Bactocount Bentley Instruments) and standard plate count, respectively. The linear equations of correlation between IBC and CFU had similar patterns in both seasons, dry and rainy, indicating that a single equation can be used to transform IBC results in CFU along the year. The linear equation was defined as $\log (\mathrm{CFU})=0.7224 \mathrm{x} \log (\mathrm{IBC})+1.4617$ with coefficient of correlation of 0.8125 . The accuracy of Bactocount in estimating reference values, denoted by the standard error $(\mathrm{s}(\mathrm{y}, \mathrm{x}))$, was $0.309 \log \mathrm{CFU} / \mathrm{mL}$. The results showed that Bactocount can be calibrated to express total bacterial count in CFU and, consequently, be used as an alternative method to monitor milk quality in the country.

\subsection{Introdução}

Um dos fatos mais importantes para o setor leiteiro nos últimos anos foi a aprovação da Instrução Normativa 51 (IN-51), do Ministério da Agricultura Pecuária e Abastecimento (MAPA), que determina novas variáveis de avaliação da qualidade do leite cru. De acordo com a IN-51, análises de contagem bacteriana total (CBT), 
contagem de células somáticas (CCS) e composição, de todo leite cru produzido no país e processado em estabelecimentos sob fiscalização federal, deverão ser realizadas mensalmente em um dos laboratórios credenciados pelo MAPA (BRASIL, 2002).

Para atender a demanda por estas análises, o MAPA criou a Rede Brasileira de Laboratórios de Análise da Qualidade do Leite (RBQL), composta atualmente por sete laboratórios centralizados que possuem equipamentos automatizados de última geração e de alto rendimento analítico.

A determinação da CBT poderá ser efetuada por meio do equipamento Bactocount (Bentley Instruments), o qual emprega a técnica de citometria de fluxo. Esta técnica consiste na adição de brometo de etídio (corante específico de DNA e RNA) ao leite, para que o DNA e RNA das bactérias sejam corados. O leite com o corante é injetado num capilar acoplado a um sistema óptico, que recebe, constantemente, um feixe de laser. Ao passar por este feixe, cada bactéria emite fluorescência, a qual é captada pelo sistema óptico (Barrientos et al., 2000; Broutin, 2004; Gunasekera et al., 2000; Suhren et al., 1999), e com isso o número de bactérias é determinado, sendo expresso em contagem individual de bactérias (CIB).

Esta metodologia analítica possibilita a utilização de conservantes bacteriostáticos que reduzem a atividade metabólica das bactérias, prolongando a vida útil da amostra destinada para tal análise. O conservante mais recomendado, atualmente, é o azidiol. Há citações na literatura de que amostras conservadas com azidiol podem ser analisadas em até quatro dias após a coleta, se mantidas sob refrigeração à $4{ }^{\circ} \mathrm{C}$ (Barcina et al., 1987; Gonzalo et al., 2003; Ninane et al., 2000).

No método de referência para CBT, uma alíquota de leite é distribuída em placa com meio de cultura e incubada a $30{ }^{\circ} \mathrm{C}$ por 72 horas (International Dairy Federation, 1991). Bactérias viáveis e que cresçam nestas condições, desenvolvem colônias que são enumeradas, sendo o resultado expresso em unidades formadoras de colônia (UFC). Um aspecto negativo do método de referência é o de subestimar a quantidade total de bactérias no leite, uma vez que nem sempre uma colônia é originada de apenas uma única bactéria. Este é dos motivos porque a CIB pode ser duas ou três vezes superior ao número de UFC (Gunasekera et al., 2003; Broutin, 2004). 
O limite legal para a CBT previsto na IN-51, foi estabelecido em UFC. Isto implica na necessidade de se desenvolver uma equação de correlação entre os métodos de referência e de citometria, para que os resultados expressos em CIB sejam transformados em UFC.

Países da Europa vêm adotando diferentes estratégias para adequação desta nova metodologia. Na Alemanha, por exemplo, foi elaborada uma única equação de calibração para todos os laboratórios. Na França, Holanda e Bélgica, no entanto, cada laboratório desenvolveu a equação para seus equipamentos (Broutin, 2004).

Vários trabalhos mostram uma boa correlação entre os métodos automatizado e o de contagem em placas, porém, neles, ressalta-se a importância de se utilizar um grande número de amostras de leite da região que será monitorada, uma vez que existem vários fatores que podem interferir nesta correlação (Broutin, 2004; Ninane et al., 2000; Gunasekera et al., 2000; Suhren et al., 1999). Os principais fatores citados são a microbiota predominante no leite (Gram positiva ou negativa), tamanho e formato da célula bacteriana, assim como características de agregação destas células (Suhren \& Reichmuth, 2000).

Em função do exposto, o presente trabalho teve como objetivo determinar a equação de correlação entre o método referência (UFC) e o método de citometria de fluxo (CIB). Com esta equação, os resultados de CIB podem ser transformados em UFC e utilizados no monitoramento da qualidade do leite proposto pela IN-51.

\subsection{Material e Métodos}

\subsubsection{Coleta e conservação das amostras de leite}

Foram coletadas 223 amostras provenientes de aproximadamente 45 fazendas situadas no estado de Minas Gerais e São Paulo, onde estão sediadas algumas indústrias que monitoram a qualidade do leite no laboratório da Clínica do Leite do Departamento de Zootecnia da Escola Superior de Agricultura “Luiz de Queiroz”, em Piracicaba, São Paulo. 
As coletas foram realizadas nos meses de junho, julho, setembro, novembro e dezembro de 2004. Três rotas de captação foram selecionadas e seis transportadores treinados quanto aos procedimentos corretos de coleta das amostras.

Procurou-se manter a coleta sempre nas mesmas fazendas, salvo em casos de inclusão ou saída de fazendas na rota de coleta.

Em cada fazenda foi coletada amostra de $50 \mathrm{~mL}$ de leite em frasco esterilizado e encaminhada para a indústria. As amostras vindas de diferentes rotas de captação foram agrupadas na plataforma de recepção e enviadas para o laboratório da Clínica do Leite no final do dia de coleta.

Durante todo o processo logístico, as amostras ficaram sob refrigeração a $4{ }^{\circ} \mathrm{C}$. O tempo decorrido entre a coleta e a chegada das amostras na Clínica do Leite não ultrapassou $18 \mathrm{~h}$.

\subsubsection{Análise laboratorial}

No dia seguinte à chegada, as amostras foram subdivididas em duas outras para realização das análises pelos métodos de referência e citometria de fluxo.

Uma das amostras foi enviada para o laboratório Microbial, localizado na cidade de Campinas - SP, onde foi realizada a análise pelo método de referência. A outra amostra permaneceu na Clínica do Leite, onde se efetuou a análise por citometria de fluxo, utilizando o equipamento Bactocount (Bentley Instruments, 2004).

As análises foram realizadas em duplicata e iniciadas no mesmo horário. O tempo decorrido entre a chegada da amostra na Clínica do Leite e as análises não ultrapassou 20h.

\subsubsection{Análise estatística}

Os resultados de contagem individual de bactérias (CBI) e unidades formadoras de colônia (UFC), foram transformados para logaritmo na base dez. 
Resultados referentes aos meses de junho, julho e setembro, foram agrupados considerando-se estação seca, uma vez que neste período ocorre baixa precipitação. Já os meses de novembro e dezembro foram agrupados, considerando-se estação das águas. Efetuou-se análise de regressão linear para cada grupo, considerando o $\log (\mathrm{UFC})$ como variável dependente e o $\log (\mathrm{CIB})$ como variável independente. Posteriormente, aplicouse o teste de coincidência de retas para verificar se as mesmas eram semelhantes entre os grupos.

Também foi calculada a acurácia do equipamento Bactocount, expresso pelo desvio padrão residual do $\log (\mathrm{UFC})(\mathrm{s}(\mathrm{y}, \mathrm{x}))$ (International Dairy Federation, 1999)

\subsection{Resultados e Discussão}

Foram utilizadas 223 amostras de leite, sendo 155 referentes à estação da seca e 68 referentes à estação das águas. A distribuição das amostras, de acordo com o nível de contaminação bacteriana, pode ser observado na Tabela 1.

Tabela 1. Distribuição das amostras de acordo com o nível de contaminação bacteriana na estação da seca e das águas

\begin{tabular}{ccccccc}
\hline $\begin{array}{c}\text { Contagem individual } \\
\text { de bactérias (mil/mL) }\end{array}$ & \multicolumn{2}{c}{ Estação seca } & \multicolumn{2}{c}{ Estação águas } & \multicolumn{2}{c}{ Total } \\
\hline $0-100$ & 30 & $\mathbf{n}$ & $\mathbf{n}$ & $\mathbf{\%}$ & $\mathbf{n}$ & $\mathbf{\%}$ \\
$101-500$ & 42 & 27,1 & 12 & 17,6 & 54 & 24,2 \\
$501-1.000$ & 29 & 18,4 & 10 & 14,7 & 39 & 17,5 \\
$>1.000$ & 54 & 34,8 & 44 & 64,7 & 98 & 43,9 \\
Total & 155 & 100,0 & 68 & 100,00 & 223 & 100,00 \\
\hline
\end{tabular}

n = número amostral; Estação seca = Junho à Setembro; Estação águas = Novembro e Dezembro

Pode se observar que foram utilizadas amostras com diferentes níveis de contaminação bacteriana. Na estação das águas, foi obtido maior número de amostras com alta contagem de bactérias provavelmente em função da maior precipitação, formação de áreas com lama e conseqüentemente maior contaminação dos animais no 
momento da ordenha. A utilização de amostras com diferentes níveis de contagem bacteriana é fundamental para que a equação de calibração seja aplicável em diferentes situações (Broutin, 2004; Gunasekera et al., 2003; Suhren et al., 2000).

A Figura 1 ilustra a análise de regressão realizada para cada estação.

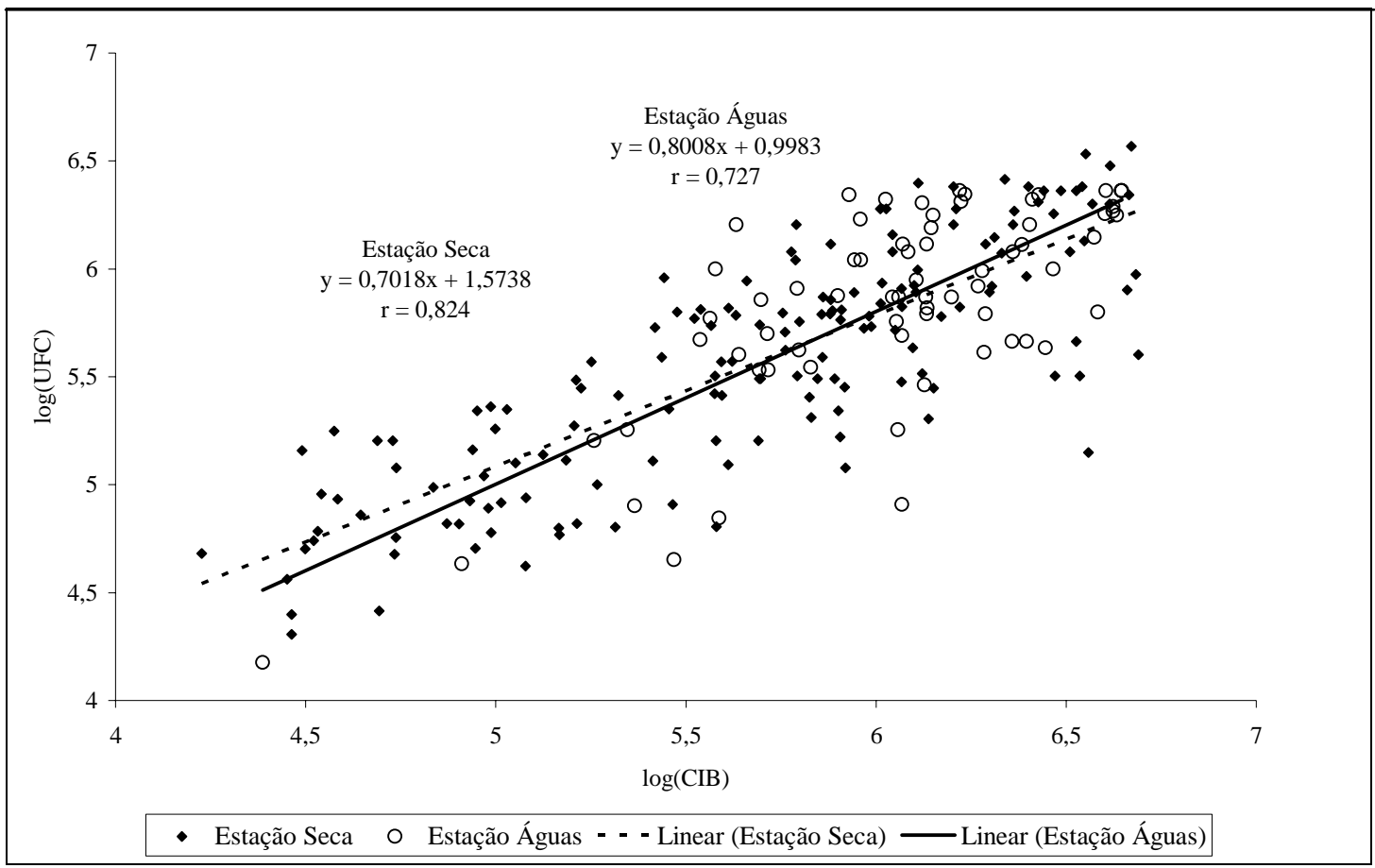

Figura 1- Dispersão entre $\log (\mathrm{CIB})$ e $\log (\mathrm{UFC})$ na estação da seca e das águas e retas ajustadas

O teste de coincidência de retas indicou que as equações obtidas são semelhantes nas duas estações ( $p=0,94)$, o que torna possível a utilização de uma única equação durante todo o ano. No entanto, Suhren et al. (2000) sugerem que seja realizado monitoramento permanente, analisando-se amostras pelos dois métodos e efetuado ajuste na equação quando necessário.

A análise de regressão linear, considerando as amostras de ambas as estações, mostrou correlação significativa entre os dois métodos com $r=0,8125$. Trabalhos 
desenvolvidos em outros países mostram uma correlação superior variando de 0,90 a 0,98 (Broudin, 2004).

A análise de resíduos não indicou a presença de dados discrepantes, bem como nenhum padrão que indicasse heterogeneidade de variância.

Como pode ser observado na Figura 2, a equação de calibração obtida foi expressa como $\log (\mathrm{UFC})=\log (\mathrm{CIB}) \times 0,7224+1,4617$.

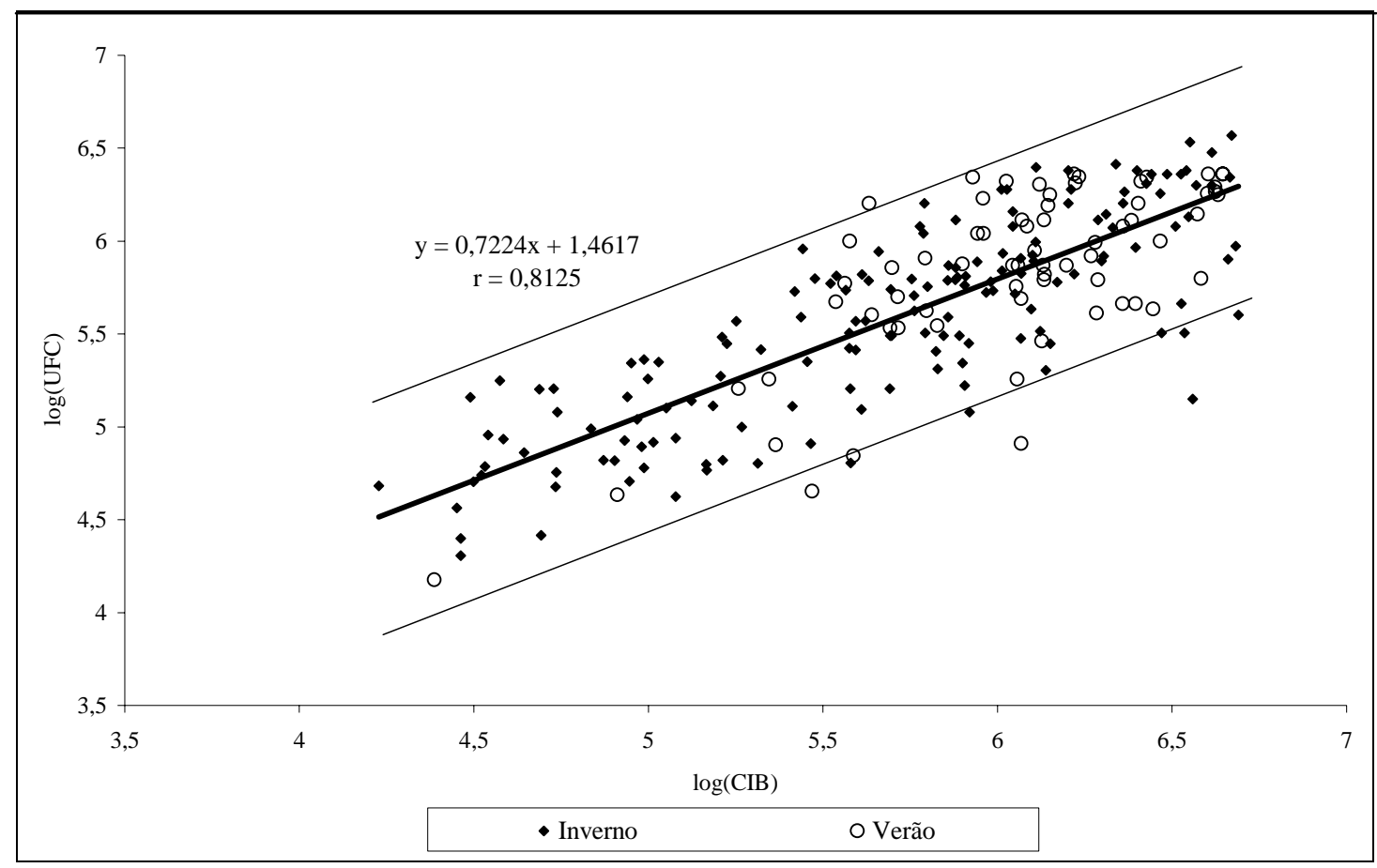

Figura 2- Dispersão entre $\log (\mathrm{CIB})$ e $\log (\mathrm{UFC})$, reta ajustada e intervalo individual de predição (95\%)

A acurácia do equipamento Bactocount na estimativa do valor de referência, expressa pelo desvio padrão $(\mathrm{s}(\mathrm{y}, \mathrm{x}))$, foi de 0,309 log UFC/mL. Considerando erro de 5 \%, o intervalo de predição individual de y é de +/- 0,607 log UFC/mL.

Trossat et al. (2002), avaliando o mesmo equipamento em 215 amostras de leite, observaram desvio padrão de 0,167 log UFC/mL. Em outros trabalhos, onde se avaliou equipamento similar ao Bactocount, observou-se desvio padrão variando de 0,25 a 0,30 $\log$ UFC/mL (Ninane et al., 2000; Suhren et al. 2000). 
O fabricante do equipamento Bactocount sugere um erro padrão inferior a 0,25 $\log$ UFC/mL (Broudin, 2004). Acredita-se que o erro padrão obtido no presente estudo foi superior em função do maior número de fatores que podem afetar a correlação. Dentre estes, a maior variação do nível de contaminação bacteriana no leite brasileiro merece destaque. Surhen et al. (2000) demonstraram que em leite onde a contagem bacteriana é reduzida, predominam bactérias Gram-positivas, enquanto que em leites de alta contagem predominam bactérias Gram-negativas. Segundo os autores, o equipamento subestima a contagem de bactérias Gram-negativas e superestima as Grampositivas quando comparado ao método de referência. No trabalho realizado por Trossat et al. (2002), em que a acurácia foi de 0,16 log UFC/mL, 78 \% das amostras possuíam contagem bacteriana abaixo de $50 \mathrm{mil} \mathrm{UFC/mL}$, e apenas $3 \%$ das amostras com contagem superior a 300 mil UFC/mL o que demonstra uma menor variação do nível de contaminação bacteriana comparado ao presente estudo (Tabela 1).

Considerando a acurácia de 0,309 $\log \mathrm{UFC} / \mathrm{mL}$, o resultado obtido pelo equipamento e transformado para UFC, pode apresentar uma grande variação em relação ao resultado que seria obtido pelo método referência (Tabela 2).

Tabela 2. Intervalo individual de predição do valor de referência, para diferentes níveis de contagem bacteriana

\begin{tabular}{|c|c|c|c|}
\hline \multirow[t]{2}{*}{ CIB $\left(\times 10^{3}\right)$} & \multicolumn{3}{|c|}{ UFC $\left(\times 10^{3}\right)$} \\
\hline & Estimado & Limite Inferior & Limite Superior \\
\hline 13 & 26 & 7 & 106 \\
\hline 25 & 44 & 11 & 176 \\
\hline 50 & 72 & 18 & 290 \\
\hline 100 & 118 & 29 & 478 \\
\hline 200 & 196 & 48 & 789 \\
\hline 400 & 323 & 80 & 1.301 \\
\hline 800 & 532 & 132 & 2.147 \\
\hline 1.600 & 878 & 218 & 3.542 \\
\hline 3.200 & 1.449 & 359 & 5.843 \\
\hline
\end{tabular}


O limite legal estabelecido pela IN-51 é de $1.000 \mathrm{mil} \mathrm{UFC/mL}$. Sendo assim, um leite analisado pelo equipamento Bactocount e que apresentou uma CBT de 1.449 mil $\mathrm{UFC} / \mathrm{mL}$ estaria fora dos padrões legais e o produtor estaria sendo penalizado. No entanto, se a mesma amostra fosse analisada pelo método de referência poderia apresentar um resultado variando de 359 a $5.843 \mathrm{mil} \mathrm{UFC/mL} \mathrm{(Tabela} \mathrm{2).}$

No caso de programas de pagamento por qualidade, onde as metas geralmente são definidas em UFC, a variação na classificação do leite pode ser ainda maior. Por exemplo, programa proposto pela Dairy Partners of America (2004) prevê que o leite com CBT abaixo de 100 mil UFC/mL seja melhor remunerado, enquanto que, leite com CBT acima de 400 mil UFC/mL seja penalizado com menor remuneração. A faixa entre 100 e 400 mil UFC/mL é considerada neutra. Um leite com CBT de 196 mil UFC/mL, determinada pelo equipamento, estaria nesta faixa. Porém, se a mesma amostra fosse analisada pelo método de referência, o resultado poderia variar de 48 a 789 mil UFC/mL, ou seja, o produtor poderia estar recebendo bonificação ou estar sendo penalizado.

É preciso lembrar que o método de citometria de fluxo enumera o total de bactérias presentes no meio, enquanto que a contagem em placas enumera somente as bactérias que tenham condições de crescer nas condições impostas do meio. Assim, pode-se considerar que o método de citometria de fluxo representaria melhor a qualidade bacteriológica do leite. Surhen et al. (2000), abordam a questão da interpretação de resultados microbiológicos na avaliação da qualidade do leite, enfatizando que a qualidade bacteriológica é um sistema multi-dimensional afetado por diferentes fatores (número de bactérias, atividade metabólica, agregação de bactérias e predominância de microbiotas). Quando se aplica um método como a contagem padrão em placas, este sistema é reduzido a uma única dimensão. Neste método, os resultados são expressos em unidades formadoras de colônia, e indicam parcialmente a qualidade bacteriológica uma vez que não se leva em consideração fatores como agregação bacteriana, atividade metabólica e microbiota predominante. Segundo os autores, não existe um único método capaz de expressar a verdadeira qualidade bacteriológica do leite. Contudo, como a contagem padrão em placas é reconhecida como método de referência e os padrões 
legais geralmente foram estipulados em UFC, os métodos alternativos devem ser referenciados a ela, porém reconhecendo-se as limitações deste tipo de ajuste.

No caso do Brasil, o método de citometria de fluxo poderia ser adotado e a CBT expressa em CIB, sem transformação em UFC como foi feito no Canadá, Reino Unido e Noruega (Broudin, 2004). Isto representaria melhor a qualidade bacteriológica do leite, sendo apenas necessário o ajuste dos limites legais.

\subsection{Conclusão}

A correlação entre os métodos de referência e de citometria de fluxo é semelhante nas estações da seca e das águas. Isto torna possível a utilização de uma única equação de calibração para o equipamento Bactocount. No entanto, devido a alta contagem bacteriana do leite brasileiro a correlação entre a contagem em placas e a citometria de fluxo não é tão alta quanto a observada em outros países. Isto faz com que o intervalo de predição dos valores estimados seja muito amplo. Sugere-se, portanto, que sejam utilizados os resultados diretamente obtidos do equipamento de citometria de fluxo, em CIB, pois representariam melhor a qualidade bacteriológica do leite. 


\section{CONCLUSÕES GERAIS}

Amostras conservadas com azidiol e mantidas sob refrigeração $\left({ }^{\circ} \mathrm{C}\right)$ podem ser analisadas em até sete dias úteis após a coleta. No entanto, deve-se garantir que o azidiol seja adicionado a amostra na quantidade adequada, que a amostra não sofra congelamento ou que a temperatura se eleve. Para atender as análises previstas na IN-51, será necessária a coleta de duas amostras de cada produtor, uma destinada à determinação de CCS e composição, contendo o bronopol e, outra, para CBT, contendo azidiol.

A correlação entre os métodos de referência e de citometria de fluxo é semelhante nas estações da seca e das águas. Isto torna possível a utilização de uma única equação de calibração para o equipamento Bactocount. No entanto, devido a alta contagem bacteriana do leite brasileiro a correlação entre a contagem em placas e a citometria de fluxo não é tão alta quanto a observada em outros países. Isto faz com que o intervalo de predição dos valores estimados seja muito amplo. Sugere-se, portanto, que sejam utilizados os resultados diretamente obtidos do equipamento de citometria de fluxo, em CIB, pois representariam melhor a qualidade bacteriológica do leite. 


\section{REFERÊNCIAS BIBLIOGRÁFICAS}

BARCINA, Y.; ROS, G.; RINCON, F. Azidiol as a preservative for milk samples. In: ANALES DE VETERINARIA DE MURCIA, Murcia, 1987. Anales. Murcia: Universidad de Murcia, 1987. p.65-69.

BARRIENTOS, A.A.; ARROYO, J.; CANTÓN, R.; NOMBELA, C. Applications of flow cytometry to clinical microbiology. Clinical Microbiology Reviews, v.13, n.2, p.167-195, 2000.

BENTLEY INSTRUMENTS. Bentley 2000: operator's manual. Chaska, 1995a. 77p.

BENTLEY INSTRUMENTS. Somacount 300: operator's manual. Chaska, 1995b. 12p.

BENTLEY INSTRUMENTS. Bactocount 150: operator's manual. Chaska, 2004. 35p.

BERTRAND, J.A. Influence of shipping container, preservative and breed on analysis of milk components of shipped samples. Journal of Dairy Science, v.79, n.1, p.145148, 1996.

BRASIL. Instrução Normativa $n^{0}$. 51, de 20 de setembro de 2002. Aprova os regulamentos técnicos de produção, identidade, qualidade, coleta e transporte de leite. Diário Oficial da União, Brasília, Seção 1, p.13, 21 set. de 2002.

BRASIL. Ministério da Agricultura Pecuária e Abastecimento. Laboratório de Referencia em Análises. Métodos analíticos oficiais para controle de produtores de origem animal e seus ingredientes. Brasília, 1999. 26 p.

BRITO, M.A.V.P. Conceitos básicos de qualidade e sanidade do gado leiteiro. Juiz de Fora: Embrapa Gado de Leite, 1999. 5p.

BROUTIN, P. Contagem individual de bactérias no leite no manejo da qualidade. In: DURR, J.W.; CARVALHO, M.P.; SANTOS, M.V. O compromisso da qualidade do leite no Brasil. Passo Fundo: UPF Editora, 2004. cap.26, p.317-333. 
CELESTINO, E.L.; IYER, M.; ROGISNK, H. The effects of refrigerated storage of raw milk on the quality of whole milk powder for different periods. International Dairy Journal, v.7, p.119-127, 1997.

COLLINS, S.J.; BESTER, B.H.; MCGILL, A.E.J. Influence of psychrotrophic bacterial growth in raw milk on the sensory acceptance of UHT skim milk. Journal of Food Protection, v.56, p.418-425, 1993.

DANSEN, A.; OLID, R.M.; PITON-MALLERET, C.; GRAPPIN, R. Evaluation du Bactoscan 8000 pour la numeration automatique et rapide de la flore microbienne du lait cru. Le Lait, v.71, p.661-670, 1991.

DAIRY PARTNERS OF AMERICA. Sistema de valorização da qualidade do leite. http://lojavirtual.nestle.com.br/arquivos/snp/SVQDPA.pdf . (11 maio 2005).

EDMONDSON, P.W. Estratégias para a produção de leite de alta qualidade. In: CONGRESSO PANAMERICANO DE QUALIDADE DO LEITE E CONTROLE DA MASTITE, 2., Ribeirão Preto, 2002. Anais. São Paulo: Instituto Fernando Costa, 2002. p.34-45.

ESTADOS UNIDOS. Food and Drug Administration. Grade “A” pasteurized milk ordinance. Washington, 2001. $57 \mathrm{p}$.

FONSECA, L.F.L.; SANTOS, M. V. Qualidade do leite e controle da mastite. São Paulo: Lemos, 2000. 175p.

GIGANTE, M.L. Importância da qualidade do leite no processamento de produtos lacteos. In: DURR, J.W.; CARVALHO, M.P.; SANTOS, M.V. O compromisso da qualidade do leite no Brasil. Passo Fundo: UPF Editora, 2004. cap.16, p.235-254.

GONZALO, C.; MARTINEZ, J.R.; CARRLEDO, J.A. Fossomatic cell-counting on ewe milk: comparison with direct microscopy and study of variation factors. Journal of Dairy Science, v.86, n.1, p.138-145, 2003.

GUNASEKERA, T.S.; ATTFIELD, P.V.; VEAL, D.A. A flow cytometry method for rapid detection and enumeration of total bacteria in milk. Applied and Environmental Microbiology, v.66, n.3, p.1228-1232, 2000.

GUNASEKERA, T.S.; VEAL, D.A.; ATTFIELD, P.V. Potential for broad applications of flow cytometry and fluorescence tecniques in microbiological and somatic cell analyses of milk. International Journal of Food Microbiology, v.85, p.269-279, 2003. 
HILLERTON, E. Contagem bacteriana no leite: importância para a indústria e medidas de controle. In: SIMPÓSIO INTERNACIONAL SOBRE QUALIDADE DO LEITE, 2., Curitiba, 2000. Anais. Curitiba: s.ed., 2000. p.26-31.

INTERNATIONAL DAIRY FEDERATION. Factors influencing the bacteriological quality of raw milk. Brussels, 1980. 4 p. (Bulletin, 120).

INTERNATIONAL DAIRY FEDERATION. Milk and milk products: enumeration of microorganisms. Brussels, 1991. 3 p. (IDF Standard, 100 B).

INTERNATIONAL DAIRY FEDERATION. Milk and milk products: methods of sampling. Brussels, 1995. 25p. (IDF Standard, 50 C).

INTERNATIONAL DAIRY FEDERATION. Milk and milk products: definition and evaluation of the overall accuracy of indirect methods of milk analysis application to calibration procedure and quality control in the dairy laboratory. Brussels, 1999. 12p. (IDF Standard, 128 A).

LESLIE, K.; KELTON, D.; DAY, K. A investigation of the relationship between the presence of Prototheca and Bactoscan counts in raw milk samples. In: INTERNATIONAL SYMPOSIUM ON MASTITIS AND MILK QUALITY, 2., Ithaca, 2001. Proceedings. Ithaca: Cornell University Press, 2001. p.135-139.

MACKENZIE, N.M.; PINDER, A.C. Flow cytometry and its applications in veterinary medicine. Research in Veterinary Science, v.42, p.131-139, 1987.

MEYER, P.M. Fatores não nutricionais que afetam as concentrações de nitrogênio uréico no leite. Piracicaba, 2003. 131p. Tese (Doutorado) - Escola Superior de Agricultura “Luiz de Queiroz”, Universidade de São Paulo.

MONARDES, H.G.; MOORE, R.K.; CORRIGAN, B.; RIOUX, Y. Preservation and storage mechanisms for raw milk samples for use in milk-recording schemes. Journal of Food Protection, v.59, n.2, p.151-154, 1996.

MURPHY, S.C.; BOOR, K.J. Trouble-shooting sources and causes of high bacteria counts in raw milk. Dairy Food and Environmental Sanititation, v.20, n.3, p.606611, 2000.

NINANE, V.; REU, K.; OGER, R.; REYBROECK, W.; GUYOT, A. Évaluation du Bactoscan FC pour la numeration des bactéries du lait cru. Le Lait, v.80, p.527-538, 2000.

PRATA, L.F. Fundamentos de ciência do leite. Jaboticabal: FUNEP, 2001. 287p. 
SAS INSTITUTE. SAS/STAT user's guide 8.0 (compact disc). Cary, 1999.

SLAGHUIS, B. Sources and significance of contaminants on different levels of raw milk production. In: SYMPOSIUM ON BACTERIOLOGICAL QUALITY OF RAW MILK, Wolfpassing, 1996. Proocedings. Brussels: International Dairy Federation, 1996. p.19-27.

SUHREN, G.; REICHMUTH, J. Interpretation of quantitative microbiological results. Milchwissenschaft, v.55, v.1, p.18-22, 2000.

SUHREN, G.; WALTE, H.G. First experiences with automation flow cytometric determination of total bacterial count in raw milk. Milchwissenschaft, v.50, v.3, p.249-275, 1999.

TROSSAT, P.H.; ROLLIER, P.; BROUTIN, P. Evaluation of the Bactocount IBC. La Lettre de Cecalait, v.30, n.40, p.34-43, 2002.

VAN DE VOORT, F.R.; KERMASHA, S.; SMITH, J.P.; MILLS, B.L. A study of the stability of record of performance milk samples for infrared analysis. Journal of Dairy Science, v.70, p.1515-1523, 1987. 